\title{
Biomimetic Hydrogels to Promote Wound Healing
}

\author{
Fei Fan ${ }^{1}$, Sanjoy Saha ${ }^{1}$ and Donny Hanjaya-Putra ${ }^{1,2,3,4 *}$ \\ ${ }^{1}$ Bioengineering Graduate Program, Department of Aerospace and Mechanical Engineering, University of Notre Dame, Notre \\ Dame, IN, United States, ${ }^{2}$ Department of Chemical and Biomolecular Engineering, University of Notre Dame, Notre Dame, IN, \\ United States, ${ }^{3}$ Harper Cancer Research Institute, University of Notre Dame, Notre Dame, IN, United States, ${ }^{4}$ Center for Stem \\ Cells and Regenerative Medicine, University of Notre Dame, Notre Dame, IN, United States
}

Wound healing is a common physiological process which consists of a sequence of molecular and cellular events that occur following the onset of a tissue lesion in order to reconstitute barrier between body and external environment. The inherent properties of hydrogels allow the damaged tissue to heal by supporting a hydrated environment which has long been explored in wound management to aid in autolytic debridement. However, chronic non-healing wounds require added therapeutic features that can be achieved by incorporation of biomolecules and supporting cells to promote faster and better healing outcomes. In recent decades, numerous hydrogels have been developed and modified to match the time scale for distinct stages of wound healing. This review will discuss the effects of various types of hydrogels on wound

OPEN ACCESS

Edited by: Guoming Sun

Hebei University, China

Reviewed by: Jun Wu,

Sun Yat-sen University, China Wenguo Cui,

Shanghai Jiao Tong University, China

*Correspondence:

Donny Hanjaya-Putra dputra1@nd.edu

Specialty section:

This article was submitted to Biomaterials,

a section of the journal Frontiers in Bioengineering and Biotechnology

Received: 31 May 2021 Accepted: 13 August 2021 Published: 20 September 2021

Citation:

Fan F, Saha $S$ and Hanjaya-Putra $D$ (2021) Biomimetic Hydrogels to

Promote Wound Healing.

Front. Bioeng. Biotechnol. 9:718377.

doi: 10.3389/fbioe.2021.718377 pathophysiology, as well as the ideal characteristics of hydrogels for wound healing, crosslinking mechanism, fabrication techniques and design considerations of hydrogel engineering. Finally, several challenges related to adopting hydrogels to promote wound healing and future perspectives are discussed.

Keywords: hydrogels, wound healing, stem cells, angiogenesis, wound dressing

\section{INTRODUCTION}

As common comorbidities of many chronic diseases, skin wounds and their associated complications are increasing in a severe rate around the world. In the United States alone, nonhealing wounds cost approximately $\$ 50$ billion, scars from surgical incisions and trauma cost nearly $\$ 12$ billion and burns cost $\$ 7.5$ billion in healthcare each year (Fife and Carter, 2012; Leavitt et al., 2016). The elderly and patients suffering from diabetes and genetic disorders like sickle cell disease are more prone to abnormal wound healing which results in long-term complications. Surprisingly mediations that exist have not significantly impacted the situation. While several approaches for wound healing are available, they are only moderately effective. Thus, there is a need for more effective therapies for healing wounds.

Hydrogels offer great advantages for wound dressing due to their mild processing conditions and their ability to incorporate many bioactive agents. The added bioactive molecules can then be delivered with a precise temporal and spatial control, which represents a great advantage in relation to their topical administration (Rice et al., 2013). Depending on the application, hydrogel properties i.e., composition, sensitivity to wound stimuli, etc. can be tailored to deliver specific mediators i.e., antiseptics, antibiotics aiming to deplete infection; antiinflammatories and antioxidants to resolve inflammation as well as critical issues in chronic 


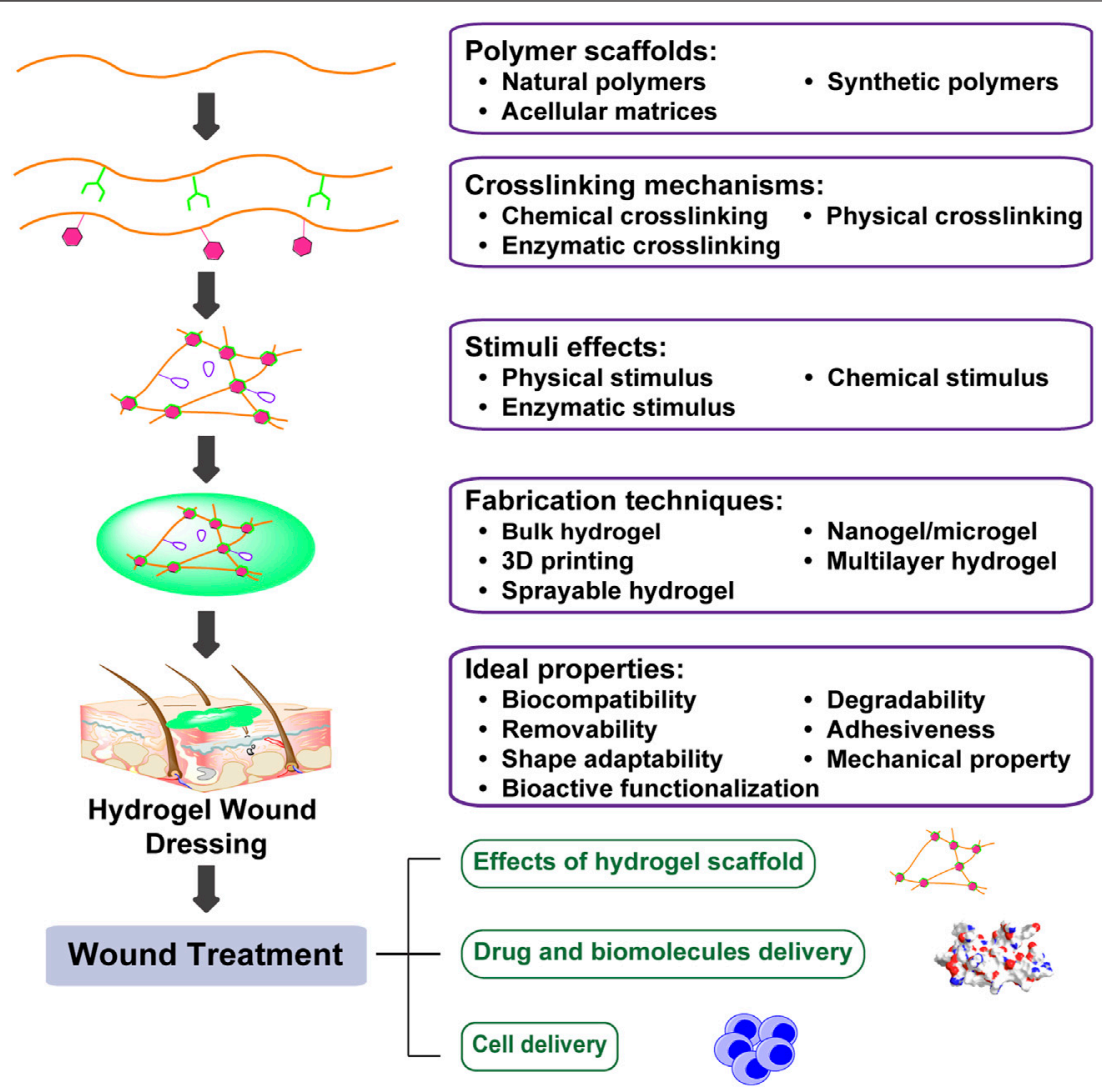

FIGURE 1 | Engineering biomimetic hydrogels to promote wound healing. Hydrogels are hydrophilic networks primarily made of polymer scaffolds by various crosslinking mechanisms. Furthermore, incorporation of stimuli effects generates hydrogels with tunable dynamics. Tuning polymer scaffolds, crosslinking mechanism, stimuli effects, as well as fabrication techniques can enhance hydrogel bioactivities and promote wound healing through drug and biomolecules delivery, as well as cell delivery.

wounds (Figure 1). Moreover, hydrogels can be used to deliver bioactive molecules known to accelerate wound healing, or to support and maximize the therapeutic potential of skin or stem cells to promote angiogenesis and re-epithelialization, as well as new extracellular matrix (ECM) production and maturation. Comprehensive understanding of hydrogel fabrication and biochemical cues of wound healing process is favorable to achieve optimum wound healing outcomes. Although there have been many articles that reviewed hydrogel dressings for wound treatment, these reviews as well as research articles usually focus on some specific aspects of hydrogel chemistry, fabrication, and application. It is important to call for the integration of hydrogel chemistry, fabrication, and biochemical cues into hydrogel dressing design with satisfying effects. Few reviews on bridging hydrogel dressing fabrication and application have been reported to date. Therefore, this review will provide an overview of various types of hydrogels on wound pathophysiology, as well as the ideal characteristics of hydrogels for wound healing, crosslinking mechanism, fabrication techniques and design considerations of hydrogel engineering.

\section{FABRICATION OF HYDROGEL FOR WOUND HEALING}

\section{Polymer Scaffolds of Hydrogel}

Natural materials, such as polysaccharides and proteins, are the most well-studied scaffolds for fabricating skin mimetic hydrogels. As one of the most predominant natural polymers, polysaccharides and proteins are biocompatible and can be extracted easily from natural resources. Polysaccharides possess abundant functional groups, such as hydroxyl, carboxyl, amine groups for versatile chemical modification, as well as endow the high-water retention ability. Cellulose (Mohamad et al., 2019), chitosan (Huang et al., 2018a), starch (Li et al., 2020), alginate (Wang et al., 2019a), kappacarrageenan (Tavakoli et al., 2020), hyaluronic acid (HA) (Zhao et al., 2020a), heparin (HP) (Wu et al., 2016), and dextran (Zhu et al., 2018) have been extensively explored for wound dressing applications (Figure 2A). Proteins, such as silk fibroin (Sproul et al., 2018), collagen (Ying et al., 2019), and gelatin (Thi et al., 2020), have more complicated structures that can promote bioactivity, which make them great candidates for fabricating wound dressings (Figure 2B). On 


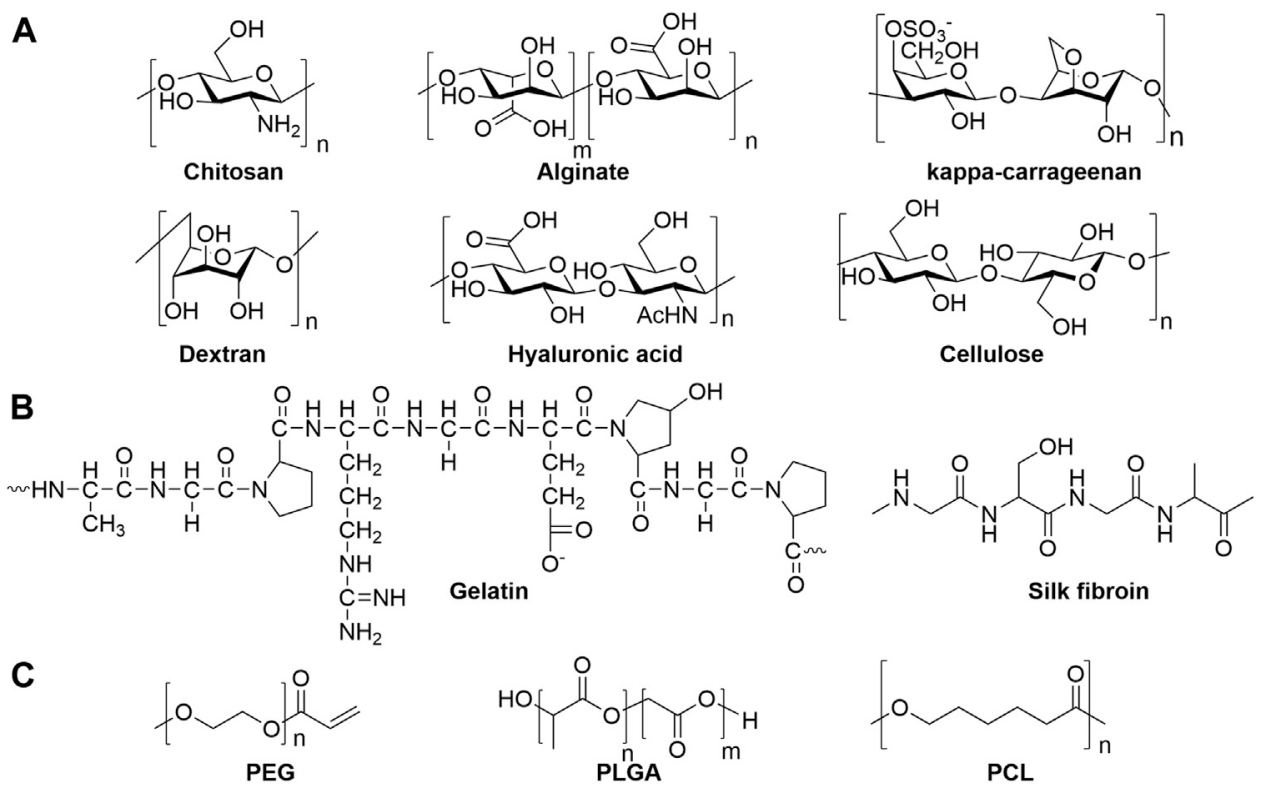

FIGURE 2 | Chemical structures of representative (A) polysaccharides, (B) proteins and (C) synthetic polymers as hydrogel scaffolds.

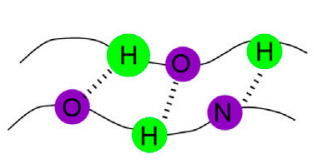

Hydrogen bond

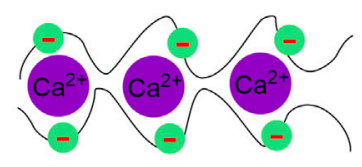

Ionic bond

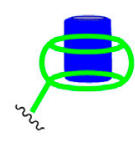

Supramolecular interaction<smiles>CCCCC(C)C</smiles>

Schiff base

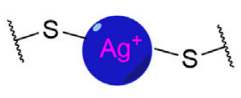

S-Ag bond

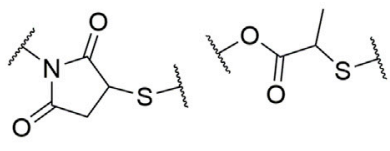

Thiol-ene addition

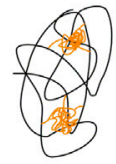

Hydrophobic interaction<smiles>Cc1ccc(O)c(-c2cc(C(F)(F)F)ccc2O)c1</smiles><smiles>CC(C)(C)c1ccc(Oc2cc(C(C)(C)C)ccc2O)cc1</smiles>

FIGURE 3 | Physical, chemical, and enzymatic crosslinking mechanisms for hydrogel fabrication.

the other hand, synthetic polymers, such as poly(lactic-coglycolic acid) (PLGA) (Chen et al., 2019a), poly(ethylene glycol) (PEG) (Chen et al., 2019b), and polycaprolactone (PCL) (Bahadoran et al., 2020) are good candidates to provide well-controlled and homogeneous polymers for hydrogels preparation (Figure 2C). Arginine-based synthetic cationic hybrid hydrogels were developed by $\mathrm{Wu}$ et al. with tunable properties which can increase the cell attachment and proliferation, as well as have great potential for ionic drugs delivery (Wu et al., 2012; Wu et al., 2014). However, the biocompatibility of synthetic polymers must be carefully examined due to their unnatural structures that could elicit immune responses.

Acellular matrices are composite materials composed of multiple natural polymers, such as polysaccharides or proteins. They retain completely analogous biochemical signaling and physical cues with good biocompatibility and low immunogenicity, which are favorable to create regenerative microenvironment for wound healing. In addition, they can facilitate adhesion, survival, and differentiation of stem cells, as well as promoting host cell infiltration and revascularization (Nie et al., 2015; Bankoti et al., 2020a). Acellular matrices can be 
isolated from full skins (Hsieh et al., 2020; Lin et al., 2020) and adipose tissues (Dongen et al., 2019; Tan et al., 2019; Pu et al., 2020). In addition, acellular matrices are genetically tunable to adjust cell invasion through thrombospondin-2 knockout resulted in faster wound healing (Morris et al., 2018).

\section{Crosslinking Mechanism}

The types of polymer crosslinking can highly affect the mechanical property of the hydrogels for wound dressing. Both reversible and irreversible crosslinking can be obtained by tuning the crosslinking mechanism. Generally, the type of polymer crosslinking can be categorized into physical and chemical crosslinking (Figure 3). Physical crosslinking includes hydrogen (Chen et al., 2021) and ionic bonds (Johnson et al., 2020), as well as hydrophobic (Wei et al., 2019), and supramolecular interactions (Zhao et al., 2020a). Physical crosslinking renders hydrogels self-healing and injectable due to their weak physical interactions. On the other hand, chemical crosslinking can afford reversible and irreversible hydrogels by applying various types of chemical bonds, such as Schiff base bond (Wang et al., 2020a), S-Ag bond (Cheng et al., 2020), and thiol-ene addition (Dong et al., 2020). More recently, enzymatic crosslinking has received significant attention due to its high efficiency and specificity, while only requiring a relatively mild reaction condition (Figure 3). The most widely investigated enzymatic crosslinking strategy is the reaction of phenol containing polymers catalyzed by horseradish peroxidase (HRP) (Tran et al., 2011; Lee et al., 2014; Liang et al., 2019a; Yao et al., 2019; Thi et al., 2020) or laccase (Wei et al., 2019). The bacterial transpeptidase Sortase A (SrtA) catalyzes polymer crosslinking enables that hydrogel formation and modification based on the ligation of LPXTGX (where X can be any amino acid except proline) and GGGG (Ham et al., 2016; Gau et al., 2017; Broguiere et al., 2018). The product of the enzymatic reaction could serve as a substrate for further transpeptidation i.e., reversible crosslinking was designed by incubating with oligoglycine substrate to tune hydrogel stiffening and softening dynamically (Arkenberg et al., 2019).

\section{Stimuli Effect}

To meet mechanical and bio-functional properties, external and internal stimuli can be incorporated into the hydrogels. Thermosensitive crosslinkers are usually utilized to control the hydrogel formation under physiological temperature through incorporation of PEG (Liu et al., 2019) or poly( $N$-isopropylacrylamide) (Luckanagul et al., 2018). These thermo-sensitive hydrogels can be injected to form hydrogels in situ and to maintain sustained drug release profile. On the other hand, photo-cleavable crosslinkers provide controlled release of antibiotics, which is triggered by UV light $(365 \mathrm{~nm})$ at low intensity (Shi et al., 2015). The light responsive prodrug hydrogel can be synthesized with nitrobenzyl moiety to provide on-demand release of drugs with reduced toxicity. To control hydrogel degradation and drug release, some chemical labile cues, such as reactive oxygen species (ROS), $\mathrm{pH}$ and glucose responsive can also be beneficial. Since ROS level in chronic wounds is higher than physiological ROS level, hydrogels crosslinked with ROS responsive linker can release encapsulated therapeutic reagent in response to wound healing process (Zhao et al., 2020b). Similarly, diabetic wounds possess higher blood glucose which could serve as a trigger of therapeutics release. Zhu et al. fabricated glucose responsive hydrogel with phenylboronate ester, such that insulin and fibroblast can be encapsulated during in situ gelation and released in response to high glucose concentration (Zhao et al., 2017a). In addition, the imbalance of protease in chronic wound can be exploited to control drug release. Wang et al. enclosed curcumin (Cur) nanoparticles into gelatin microspheres to improve bioavailability and in vivo stability of Cur (Liu et al., 2018). As a substrate of matrix metallopeptidase 9 (MMP-9), gelatin could be degraded by MMP- 9 to provide sustained release of Cur in response to MMP-9 level in chronic wound.

\section{Fabrication Techniques}

The assembly process of polymers for hydrogel fabrication is an important factor that affects hydrogel functions, which subsequently can influence wound healing outcomes. Generating bulk and amorphous hydrogels is the most convenient and widely used fabrication technique for wound dressing applications. Recently, more sophisticated techniques, such as batch emulsion, microfluidic device, extrusion fragmentation, and alternating current (AC) spray have been explored to generate microgels or nanogels hydrogels with tunable size and shape, as well as flexible degradation and mechanical properties (Sproul et al., 2018; Amato et al., 2020; Zhao et al., 2020c; Muir et al., 2021; Pan et al., 2021). To control hydrogel degradation rate matching with tissue regeneration process, Segura et al. developed injectable interconnected microporous hydrogel for which the bulk properties can be controlled through tuning the chemical and physical properties of microgel building blocks generated using a microfluidic device (Griffin et al., 2015). By patterning the gel in a syringe, the scaffold properties can be spatially controlled to match the physical location of the tissue (Darling et al., 2018). They found that the crosslinking peptide is important for hydrogel functions, the peptide crosslinker with adverse chirality showed improved immune response to induce cutaneous regenerative healing (Griffin et al., 2020). Threedimensional (3D) printing is a time- and cost-efficient fabrication to customize products with high complexity and refined performance. Some drug delivery systems have been constructed by 3D printing with excellent physico-mechanical properties (Ng et al., 2016; Hafezi et al., 2019; Long et al., 2019; Karavasili et al., 2020). Printing interconnected microchannels (Zhou et al., 2020) containing hydrogel could mimic functions of living skins that facilitates cell migration, proliferation, and new tissue formation.

Moreover, multilayer hydrogel can be engineered to combine multiple functions within bulk hydrogels in an orderly manner (Lee et al., 2012; Tavakoli et al., 2018). Skin-mimetic hydrogel can be constructed by designing multilayer hydrogel to demonstrate sequential functions similar to layered healthy skin. The upper layer could serve as a barrier for bacterial infection and controlling moist balance (Wang et al., 2019b). The lower layer can be designed to absorb excess exudate, promote 
adhesion onto the wound surface and support tissue regeneration (Tamahkar et al., 2020). Multilayer hydrogels containing a drugloaded layer provides opportunities for spatial and temporal drug release (Mohandas et al., 2015a). Recently, sprayable hydrogels are becoming more attractive for wound dressing because they demonstrate high mixing efficiency, controllable spray area, and sufficient contact with soft tissues. Usually, the sprayable hydrogels are formed in situ rapidly through physical crosslinking (Kumar and Jaiswal, 2016), Schiff base bond formation (Du et al., 2020), and crosslinking of phenol groups (Sun et al., 2020). Functional hydrogel can be constructed through incorporating antimicrobial peptide (Annabi et al., 2017) and cerium oxide nanoparticles (Cheng et al., 2021) to improve antibacterial activities and ROS-scavenging abilities. Cell-attracting chemotactic cytokines could be delivered by sprayable hydrogel for diabetic wound treatment (Yoon et al., 2016). The encapsulation of chemokines did not affect hydrogels properties while retained activities to enhance reepithelialization, neovascularization and collagen deposition resulted in accelerated wound healing. Sprayable hydrogels are effective delivery platform of various therapeutic reagents for wound treatments. Clinically, sprayable hydrogel is convenient for fabrication and administration with excellent patient adaptability.

\section{IDEAL PROPERTIES OF HYDROGELS TO PROMOTE WOUND HEALING}

Healthy skin is mainly composed of epidermis, dermis, and subcutaneous to protect body against harmful assaults and act as a physical support for the vascular and nervous system. The injury of skin lead to destruction of protective layer, thus inducing massive water loss, impaired sensation and thermoregulation, and bacterial infection (Frykberg and Banks, 2015). Wound healing is a complex and dynamic process that is regulated by a series of biomolecules and cells in an orderly manner. As a barrier between body and external environment, regeneration of skin is highly affected by innate biological process as well as the environmental stimulus. Thus, hydrogel, act as a temporary substitute of skin, would possess some specific properties to not only provide physical protection, but also accelerate wound healing. Similar to a healthy skin, hydrogel is able to absorb excess fluid and maintain a moist microenvironment. In order to support skin regeneration, an ideal hydrogel should be functionalized to possess other properties too.

\section{Biocompatibility, Degradability, and Removability}

Since hydrogel dressings are directly attached to the wound bed, it is essential that gels should be non-toxic and free of foreign body response. Thus, biocompatibility is the first prerequisite of hydrogels for wound dressing applications. Generally, hemolysis test, as well as in vitro and in vivo toxicity are performed to confirm the biocompatibility (Romić et al., 2016; $\mathrm{Li}$ et al., 2021). Using biocompatible components is a straightforward and easy way to ensure the biocompatibility of hydrogel scaffold (Hoque et al., 2017; Liang et al., 2019a; Ashoori et al., 2020). For biodegradable hydrogels, the biocompatibility of fragments after degradation should also be taken into considerations. In addition, hydrogel should be constructed with polymer solutions in high purity as well as biocompatible techniques, such as harmless UV condition (Vega et al., 2018), to avoid unexpected toxicities.

During wound healing process, hydrogel dressings need to be changed periodically to maintain high efficiency and avoid infections. Hydrogel dressing changes may not only increase the cost and decrease patient compliance, but also cause secondary injury to the wound. Clinically, wound dressing is changed more frequently for chronic wounds. Therefore, degradability and removability of hydrogels are important for administration. Grinstaff et al. (Konieczynska et al., 2016) constructed a hydrogel dressing which can be chemically removed via thiol-thioester exchange (Figures 4A,B). The ondemand dissolvable hydrogel is promising for second-degree burn. To fit the typical dressing change frequency of diabetic wounds, thioether grafted hyaluronic acid nanofibrous hydrogel was fabricated by Huang et al. (Liu et al., 2020a) which can be degraded and absorbed gradually within 3 days (Figure 4C). This hydrogel can synergistically modulate the inflammation in diabetic wound via scavenging ROS and promoting the transformation of M1 macrophages to M2 phenotype. In addition, to meet the needs of dressing changing via hydrogel degradation, therapeutic release from hydrogel can be regulated by cleaving hydrogel scaffold in the presence of physical, chemical or enzymatic stimuli. Thus, therapeutic reagents release can be coordinated with sequential phases of wound healing to achieve optimal skin regeneration (Huang et al., 2018a; Chen et al., 2019a; Ma et al., 2020).

\section{Adhesiveness}

Hydrogels for wound dressing applications need to adhere firmly to cover the open wound and to provide protective microenvironment for wound healing. At the first phase of wound healing, it is important for hydrogel to act as hemostatic material to stop bleeding rapidly. Besides, firmly adhering hydrogels functions to prevent the leakage of fluid or gas from the wound and avoiding bacterial infections. Mussel inspired catechol moiety is widely applied to improve adhesiveness through the imide formation or Michael-type reaction of catechol or quinone groups with amino or thiol groups on the protein (Ku et al., 2010). Guo et al. prepared a series of antibacterial adhesive hydrogels by incorporating catechol into hydrogel with adhesive strength of around $6 \mathrm{kPa}$ which increase to around $30 \mathrm{kPa}$ after incubation under $37^{\circ} \mathrm{C}$ for $1 \mathrm{~h}$ (Liang et al., 2019a; Liang et al., 2019b; Zhao et al., 2020d). Because of their good tissue adhesiveness, the hydrogels demonstrated hemostatic ability. Moreover, the addition of catechol groups enhanced antioxidant activity, which endow multiple properties by functionalizing with catechol groups. The other type of adhesive hydrogels is created using the Schiff base reaction between aldehyde group on hydrogels and amino groups from tissues to afford adhesive strength around 

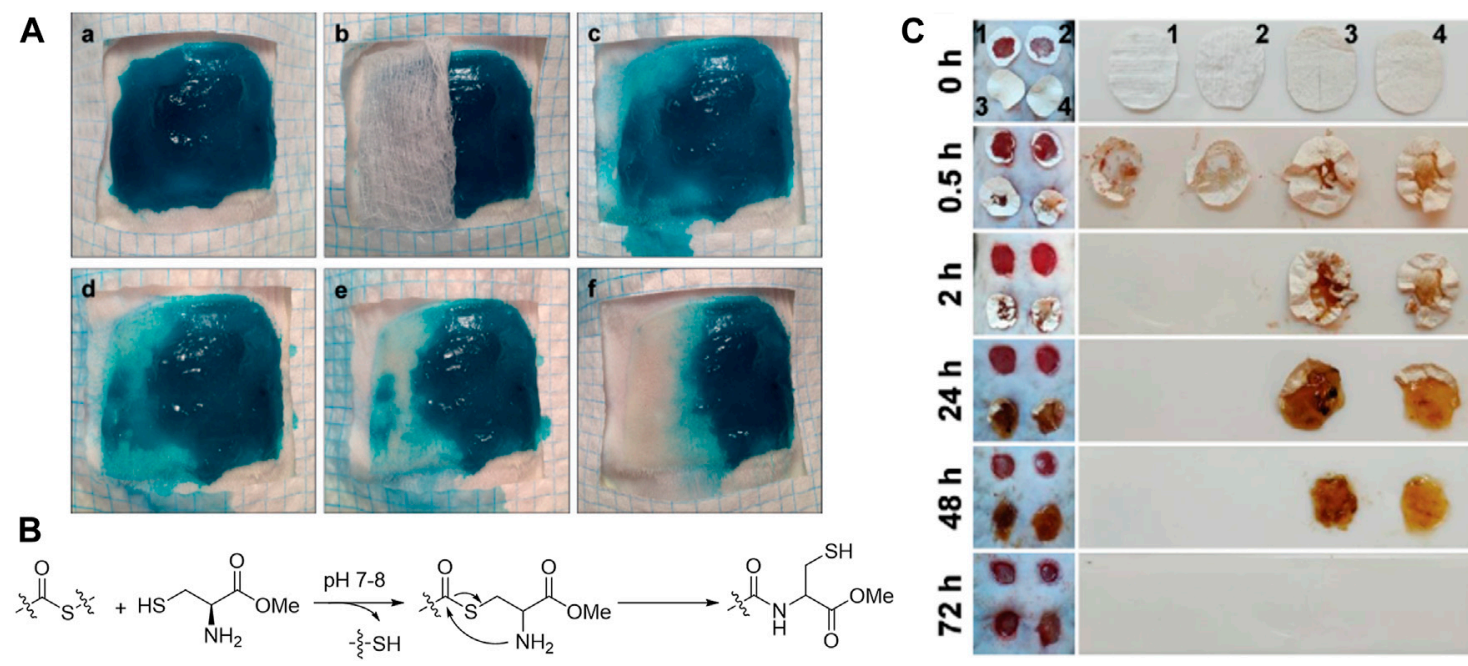

FIGURE 4 | (A) Dissolution of the hydrogel after treatment with an aqueous cysteine methyl ester (CME) solution (0.3 m, pH 8.6) via thiol-thioester exchange (B) (Konieczynska et al., 2016). Images were adapted with permission from Konieczynska et al. (2016). Copyright 2016, John Wiley and Sons. (C) Degradation of different nanofibrous hydrogel (1 FHHA, 2 FHHA-S, 3 FHHA/Fe, and 4 FHHA-S/Fe) (Liu et al., 2020a). Crosslinking with Fe ${ }^{3+}$ increased the in vivo stability of hydrogel. FHHA, high molecular weight HA fibers; FHHA-S, thioether grafted high molecular weight HA fibers; FHHA/Fe, Fe ${ }^{3+}$ crosslinked high molecular weight HA nanofibrous hydrogel; FHHA-S/Fe, Fe ${ }^{3+}$ crosslinked thioether grafted high molecular weight HA nanofibrous hydrogel. Images were adapted with permission from Liu et al. (2020a). Copyright 2020, John Wiley and Sons.
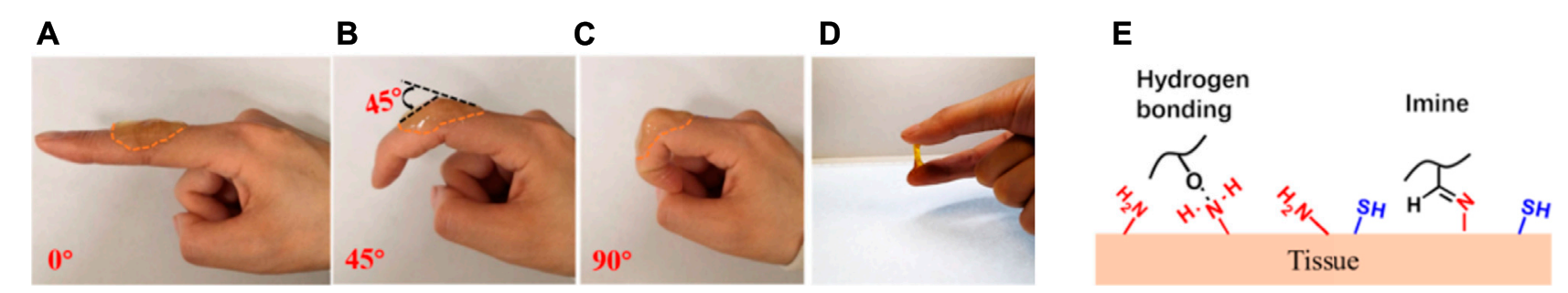

FIGURE 5|Adhesion of CHI/ACHI5-5 hydrogel. (A) Finger extended at $0^{\circ}$ with hydrogel attached, (B) finger flexed to $45^{\circ}$ with hydrogel attached, (C) finger flexed to $90^{\circ}$ with hydrogel attached, (D) hydrogel adhered to two fingers, (E) the mechanism of adhesion through hydrogen bond and Schiff base formation (Wang et al., 2020 b). $\mathrm{CHI}$, chitosan; ACHI, aldehyde-chitosan. Images were adapted with permission from Wang et al. (2020b). Copyright 2020, American Chemical Society.

$6 \mathrm{kPa}$ (Zhao et al., 2017b). The shear-thinning behavior based on dynamic Schiff base formation endow self-healing properties and stable attachment on skin tissue with intersection angle from 0 to 90 (Figure 5) (Li et al., 2018; Li et al., 2020; Wang et al., 2020b).

\section{Shape Adaptability}

Since the wound area is usually irregular, incomplete coverage of wound dressing would lead to delayed healing and bacterial infections. Therefore, the hydrogels need to ensure complete cover over wound bed through rapid shape adaptability (e.g., reversable crosslinking). Guo et al. constructed PEG based thermo-responsive hydrogels that can automatically change shape under $37^{\circ} \mathrm{C}$ rapidly without external stimulation (Zhao et al., 2020d). Injection or in situ formation of hydrogel (Gao et al., 2020) is a good technique to achieve complete coverage over wound bed. Before injection, it is a prepolymer solution or shearthinning hydrogel. After injection, the prepolymer solution can spread over wound area and then form hydrogel in situ to cover it (Zhao et al., 2017a; Wang et al., 2019c) or by controlling injection to fill irregular wounds (Lokhande et al., 2018; Chen et al., 2019b) with minimal invasion and pain. Sprayable hydrogel is an emerging approach for wound management to offer an in situ forming, tunable and shape adaptable coverage without fluting in wound area (Kumar and Jaiswal, 2016; Yan et al., 2019; Du et al., 2020). It would be the most convenient approach with excellent patient compliance.

\section{Mechanical Property}

Mechanical protection is a fundamental function of wound dressings, especially for their application at joint sites where motion and bending occurs frequently. Mechanical failure will lead to nutrients loss, wound exposure, and infection. To improve comfort and convenience, appropriate mechanical properties, including stiffness, strength, stretchability and compressibility, 
should be tuned based on the type and location of the wounds. The mechanical properties can be controlled by tuning the types of components, formulations, and crosslinkers. Shen et al. fabricated a nanocomposite hydrogel (XKP) by introducing polydopamine nanoparticles (PDA NPs) into a food gum matrix (XG and KGM) with excellent elasticity (Zeng et al., 2021). The low substance content $(0.4 \% \mathrm{XG}, 0.6 \% \mathrm{KGM}$, and $0.1 \%$ PDA NPs), high porosity, and a strong swelling property endowed deformation and shape recovery, while dynamic crosslinking between PDA NPs and polysaccharides kept the hydrogel is intact. Guo et al. constructed micelle/hydrogel composites with benzaldehyde-terminated Pluronic ${ }^{\circledR} \mathrm{F} 127$ (PF127-CHO) and quaternized chitosan (QCS) through dynamic Schiff base bond (Qu et al., 2018). The composite hydrogel exhibited excellent mechanical tolerance including bending, compression, stretching, twisting, and knotting. In addition to nanoparticle or micelle composite hydrogel, multiples mechanical properties can be hybridized and adjusted by preparing double network hydrogel. Varma et al. designed an ultra-tough and self-healable double-network hydrogel based on the hydrogen bonds and Schiff-base bond between oxidized salep and ethylene diamine-modified salep to create self-healing ability and interaction of hydroxyl groups between poly(vinyl alcohol) to enhance hydrogel toughness (Tavakolizadeh et al., 2021). Guo et al. prepared doublenetwork hydrogel through catechol- $\mathrm{Fe}^{3+}$ coordination between poly(glycerol sebacate)-co-poly(ethylene glycol)-g-catechol prepolymer (PEGSD) and $\mathrm{Fe}^{3+}$ and quadrupole hydrogen bonding of ureido-pyrimidinone modified gelatin (GTU) (Zhao et al., 2020d). Both double-network hydrogels were extensible and compressible, while maintaining enhanced stability and toughness. In order to maintain complete coverage over wound area and minimize secondary injury induced by sliding of hydrogel dressing during motion and bending, hydrogels would also need to exhibit excellent adhesiveness to tissues. In unexpected conditions of hydrogel rupture, hydrogels should be able to selfheal to prevent failure. Fortunately, the tuning of crosslinking mechanism and polymer components to achieve good stretchability, compressibility, adhesiveness, and self-healing are similar. Therefore, those properties could be taken into consideration when designing hydrogel functions.

\section{Bioactive Functionalization}

With the skin-mimetic hydrogels as protective barriers to insulate wound bed, the addition of bioactive into the hydrogels is essential to improve wound microenvironment and to promote tissue regeneration. Some polymers, such as polycationic chitosan, may exhibit bioactivities and show anti-bacterial effect (Ahmed and Ikram, 2016), utilizing those polymers for hydrogel fabrication would reduce additional additives thus benefits quality control. Beta-1,3/1,6-glucan $(\beta G)$ is a polysaccharide with immunological and inflammatory activities. Incorporation of $\beta G$ increased the epithelialization and wound contraction in the diabetic male mice (Grip et al., 2017). Sun et al. performed chemical modifications of dextran hydrogels to promote wound healing in vivo. Amine modification of dextran hydrogel scaffolds enhanced biocompatibility and integration with the host tissue. The hydrogel formed with the allyl modified dextran and PEG diacrylate could promote neovascularization and skin regeneration in third-degree burn wounds (Figure 6A) (Sun et al., 2011). Replacing the allyl with methacrylate promoted biocompatibility of hydrogel and complete skin regeneration with hair regrowth on both pre-existing scars and acute wounds (Figure 6B) (Sun, 2017). Glycosaminoglycan (GAGs) is a type of polyanion polysaccharides that have been widely explored for clinical application. Among them, heparin is currently the most promising, though the mechanism of its bioactivities is largely unclear. The most acceptable assumption is the electrostatic interactions of positively charged amino acid residues of proteins and negatively charged sulfate groups of heparins. Applying heparin in hydrogel wound dressing helped to rescue defective diabetic wound healing via effective scavenging of the inflammatory chemokines, as well as increased granulation tissue formation and vascularization (Figure 6C) (Lohmann et al., 2017). Xiao et al. explored the incorporation of heparin for growth factors (GFs) loading, the results showed that stronger interactions of GFs with heparin slowed down GFs released from HP hydrogels leading to less wound healing efficiency (Wu et al., 2016). Deciphering bioactivities of polymers for hydrogel preparation is still challenging, but it would render hydrogels with various therapeutic effect in a straightforward manner.

Electroactivity is an important property of hydrogels to promote activities of important cells for wound healing, such as fibroblasts, keratinocytes, nerve, bone, muscle, cardiac, and mesenchymal stromal cells (Guo and Ma, 2018). Conductive hydrogel is an emerging hydrogel with electroactivity to promote wound healing. Polyaniline (Zhao et al., 2017b), carbon nanotubes (CNT) (Liang et al., 2019b) and graphene oxide (GO) (Liang et al., 2019a; Liang et al., 2020) have been utilized by Guo and coworkers for hydrogel wound dressing preparation with conductivity up to $5 \mathrm{mS} / \mathrm{cm}$. Incorporation of conductive component showed excellent wound healing effect with thicker granulation tissue. However, conductive hydrogels usually have poor adhesiveness, thus composite hydrogels can be designed to improve the mechanical properties. Inclusion of dynamic Schiff base bond and catechol moiety endowed excellent stretching, compression, and bending property. As a porous structure, hydrogel dressings can be used to deliver therapeutic agents, such as drugs and proteins, as well as cells to improve antimicrobial, anti-inflammatory and pro-angiogenesis functions which will be discussed below.

\section{Optimizing Biomimetic Properties}

With the development of wound dressing, more complex properties are expected to be integrated into wound dressings instead of simple physical coverings. The occurrence of wound results in loss of biochemical and cell properties as well as induction of infections. Consequently, hydrogels which mimic the biochemical and mechanical properties of target tissues can improve the effects of hydrogel system. Versatile polymer and crosslinking mechanisms can be utilized to tune stiffness, porosity, adhesiveness, and degradability to adapt to the needs of wounds. Modifications are needed for both natural and synthetic polymers to achieve optimum properties, while acellular matrices (Nie et al., 2015; Lin et al., 2020) can 


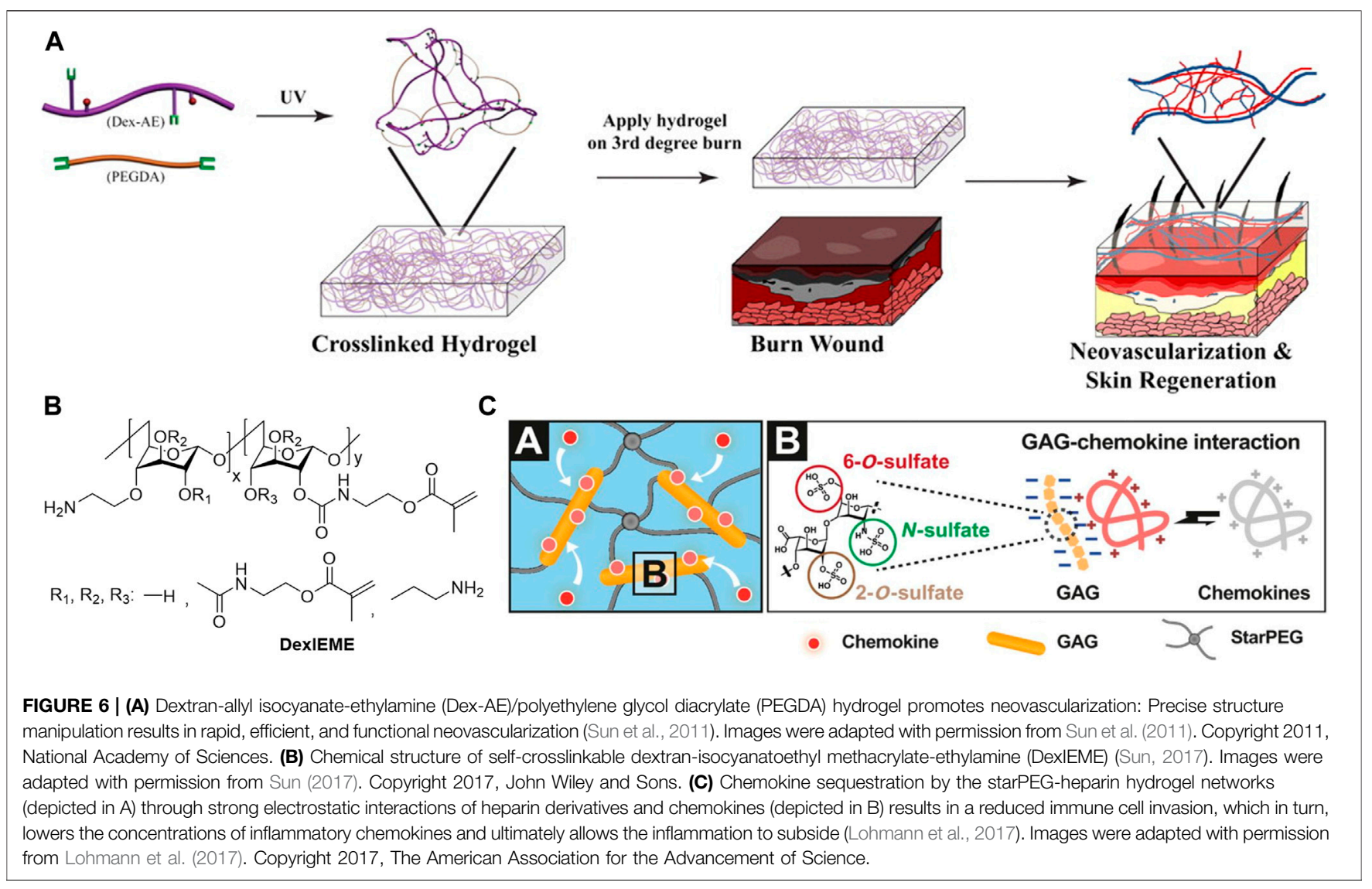

maintain biological and mechanical properties of natural tissues with minimum modifications. Moreover, fabrication techniques, such as microgel (Griffin et al., 2015; Muir et al., 2021) multilayer, (Li et al., 2019), and 3D printing (Wan et al., 2019) are effective strategies for complicated hydrogel system design based on widely used hydrogel scaffold. To mimic wound healing dynamics, various chemical, physical, and protease stimuli effects are essential for rapid and reversible responses, which match the release profile of drugs to support cell migration and proliferation. Furthermore, by spatiotemporal incorporation of biological cues and harnessing the bioactivities of hydrogel scaffold (Wang et al., 2021), the biomimetic hydrogels can be designed to mimic the native ECM for cell delivery and tissue regeneration (Orive et al., 2009; Wang et al., 2018). At this point, deciphering the biochemical cues of wound microenvironment (Chang, 2016; Sodhi and Panitch, 2021) is of a great value for biomimetic hydrogel design. By understanding the process of hydrogel preparation and biochemical cues of wound microenvironments, many aspects of biomimetic hydrogels can be altered systematically to optimize its effects on wound treatment.

\section{APPLICATION OF HYDROGELS}

The etiology of the chronic skin wound is variable and not completely understood. Pathophysiology of chronic skin wounds reveals that different cellular and molecular mechanisms are impaired in wound healing. Though wound healing should occur following a coordinated sequence of hemostasis, inflammation, proliferation, and remodeling; in many cases of chronic wounds, it stalls at inflammatory stage. Patients with vascular damage have less blood flow to the site of injury which causes impaired immune response and eventually infections (Naghibi et al., 1987; Moore et al., 1997; Maruyama et al., 2007). With the onset of infection, the wound bed becomes proinflammatory due to high levels of mediators secreted by the immune cells (Loots et al., 1998; Zhao et al., 2013). But the inability of the immune cells to eliminate infection leads to a persistent stage of inflammation that restricts the wound from progressing to proliferative stage (Loots et al., 1998; Zhao et al., 2013). Poor wound healing is not only due to the improper blood supply but also due to compromised angiogenesis due to decrease in angiogenic molecules (Armstrong et al., 2007; Barrientos et al., 2008) and downstream re-epithelialization is also weakened, possibly because of the decreased proliferation and migration of keratinocytes (Thamm et al., 2015). All these chronic events, ultimately leads to disintegration of ECM due to imbalance between matrix metalloproteinase and tissue inhibitor metalloproteinase (Trengove et al., 1999). As, it is evident that chronic wounds can be due to problem of one or multiple stages of healing, there are multitude of hydrogels that focus on single or various aspect of the canonical stages of wound healing. For example, hydrogel scaffold itself can be made from antiseptic or anti-bacterial material to avoid infection. Moreover, to promote angiogenesis, various growth factors can be included and 
TABLE 1 | The fabrication and application of hydrogels for wound healing.

\begin{tabular}{|c|c|c|c|c|c|c|c|c|}
\hline $\begin{array}{l}\text { Type } \\
\text { of } \\
\text { application }\end{array}$ & Cargo & $\begin{array}{l}\text { Polymer } \\
\text { scaffold }\end{array}$ & Crosslinking & $\begin{array}{l}\text { Stimuli } \\
\text { effect }\end{array}$ & Fabrication & Property & Outcome & References \\
\hline \multirow[t]{4}{*}{$\begin{array}{l}\text { Effects of } \\
\text { hydrogel } \\
\text { scaffold }\end{array}$} & & $\begin{array}{l}\text { QCS and Pluronic }{ }^{\circledR} \\
\text { F127 }\end{array}$ & Schiff base bond & $\mathrm{pH}$ & $\begin{array}{l}\text { Bulk } \\
\text { hydrogel }\end{array}$ & $\begin{array}{l}\text { Self-healing, } \\
\text { extensibility, } \\
\text { compressibility } \\
\text { and } \\
\text { adhesiveness }\end{array}$ & $\begin{array}{l}\text { Antibacterial QCS } \\
\text { improved wound } \\
\text { healing effect }\end{array}$ & Qu et al. (2018) \\
\hline & & DexIEME & $\begin{array}{l}\text { Crosslinking of } \\
\text { alkene }\end{array}$ & & $\begin{array}{l}\text { Bulk } \\
\text { hydrogel }\end{array}$ & & $\begin{array}{l}\text { Restored full skin } \\
\text { structures on both } \\
\text { pre-existing scars } \\
\text { and acute wounds } \\
\text { by modulating } \\
\text { immune }\end{array}$ & Sun (2017) \\
\hline & & starPEG and heparin & $\begin{array}{l}\text { Thiol-ene } \\
\text { addition }\end{array}$ & & $\begin{array}{l}\text { Bulk } \\
\text { hydrogel }\end{array}$ & & $\begin{array}{l}\text { Scavenged } \\
\text { inflammatory } \\
\text { chemokines for } \\
\text { diabetic wound } \\
\text { healing }\end{array}$ & $\begin{array}{l}\text { Lohmann et al. } \\
\text { (2017) }\end{array}$ \\
\hline & & $\begin{array}{l}\text { Catechol modified PEG } \\
\text { and UPy modified } \\
\text { gelatin }\end{array}$ & $\begin{array}{l}\text { Catechol-Fe }{ }^{3+} \\
\text { coordination and } \\
\text { UPy hydrogen } \\
\text { bond }\end{array}$ & $\begin{array}{l}\text { Near- } \\
\text { infrared } \\
\text { and } \mathrm{pH}\end{array}$ & $\begin{array}{l}\text { Bulk } \\
\text { hydrogel }\end{array}$ & $\begin{array}{l}\text { Adhesiveness, } \\
\text { shape } \\
\text { adaptability, self- } \\
\text { healing, } \\
\text { antioxidant, } \\
\text { photothermal } \\
\text { antibacterial, } \\
\text { degradability and } \\
\text { removability }\end{array}$ & $\begin{array}{l}\text { Promoted full- } \\
\text { thickness wound } \\
\text { healing by regulating } \\
\text { inflammation, } \\
\text { accelerating collagen } \\
\text { deposition, } \\
\text { granulation tissue } \\
\text { formation, and } \\
\text { vascularization }\end{array}$ & $\begin{array}{l}\text { Zhao et al. } \\
\text { (2020d) }\end{array}$ \\
\hline \multirow[t]{5}{*}{$\begin{array}{l}\text { Drug and } \\
\text { biomolecule } \\
\text { delivery }\end{array}$} & hEGF & PEG and heparin & $\begin{array}{l}\text { Thiol-ene } \\
\text { addition }\end{array}$ & & $\begin{array}{l}\text { Bulk } \\
\text { hydrogel }\end{array}$ & & $\begin{array}{l}\text { Accelerated wound } \\
\text { healing by hEGF } \\
\text { delivery }\end{array}$ & $\begin{array}{l}\text { Goh et al. } \\
(2016)\end{array}$ \\
\hline & VEGF & starPEG and heparin & Amidation & & $\begin{array}{l}\text { Bulk } \\
\text { hydrogel }\end{array}$ & & $\begin{array}{l}\text { Sustained release of } \\
\text { VEGF with low } \\
\text { anticoagulant activity } \\
\text { and promotion of } \\
\text { angiogenesis for } \\
\text { diabetic wounds }\end{array}$ & $\begin{array}{l}\text { Freudenberg } \\
\text { et al. (2015) }\end{array}$ \\
\hline & $\begin{array}{l}\text { EGF } \\
\text { and Cur }\end{array}$ & $\begin{array}{l}\text { Copolymer of lactic acid } \\
\text { and reverse } \\
\text { Pluronic }{ }^{\circledR} 10 R 5\end{array}$ & $\begin{array}{l}\text { Thermo-gelling } \\
\text { behavior }\end{array}$ & Temperature & $\begin{array}{l}\text { In situ } \\
\text { gelation }\end{array}$ & & $\begin{array}{l}\text { Increased } \\
\text { granulation tissue } \\
\text { formation, collagen } \\
\text { deposition, and } \\
\text { angiogenesis }\end{array}$ & $\begin{array}{l}\text { Guo et al. } \\
(2016)\end{array}$ \\
\hline & $\begin{array}{l}\text { CeONs and } \\
\text { AMPs }\end{array}$ & Gelatin methacryloyl & $\begin{array}{l}\text { Crosslinking of } \\
\text { alkene }\end{array}$ & & $\begin{array}{l}\text { Sprayable } \\
\text { hydrogel }\end{array}$ & $\begin{array}{l}\text { Sprayability, } \\
\text { adhesiveness, } \\
\text { antioxidant and } \\
\text { antibacterial }\end{array}$ & $\begin{array}{l}\text { Enhanced wound } \\
\text { healing speed and } \\
\text { promoted } \\
\text { remodeling of the } \\
\text { healed skin }\end{array}$ & $\begin{array}{l}\text { Cheng et al. } \\
(2021)\end{array}$ \\
\hline & BG and DFO & Sodium alginate & Ionic bond & & $\begin{array}{l}\text { In situ } \\
\text { injection }\end{array}$ & & $\begin{array}{l}\text { Enhanced } \\
\text { vascularization in } \\
\text { diabetic wound by } \\
\text { promoting HIF-1a } \\
\text { and VEGF } \\
\text { expression }\end{array}$ & $\begin{array}{l}\text { Kong et al. } \\
\text { (2018) }\end{array}$ \\
\hline \multirow[t]{2}{*}{ Cell delivery } & hASCs & Gelatin & Schiff base bond & & $\begin{array}{l}\text { Microgel } \\
\text { injection }\end{array}$ & & $\begin{array}{l}\text { Provided } \\
\text { functionalized micro- } \\
\text { niches for hASCs } \\
\text { proliferation and } \\
\text { growth factors } \\
\text { secretion }\end{array}$ & $\begin{array}{l}\text { Zeng et al. } \\
(2015)\end{array}$ \\
\hline & BMSCs & $\begin{array}{l}N \text {-isopropylacrylamide } \\
\text { polymers }\end{array}$ & $\begin{array}{l}\text { Thermo-gelling } \\
\text { behavior }\end{array}$ & & $\begin{array}{l}\text { Bulk } \\
\text { hydrogel }\end{array}$ & & $\begin{array}{l}\text { Inhibited chronic } \\
\text { inflammation and } \\
\text { promoted growth } \\
\text { factor secretion } \\
\text { (Continued on }\end{array}$ & $\begin{array}{l}\text { Chen et al. } \\
\text { (2015) }\end{array}$ \\
\hline
\end{tabular}


TABLE 1 | (Continued) The fabrication and application of hydrogels for wound healing.

\begin{tabular}{|c|c|c|c|c|c|c|c|c|}
\hline $\begin{array}{l}\text { Type } \\
\text { of } \\
\text { application }\end{array}$ & Cargo & $\begin{array}{l}\text { Polymer } \\
\text { scaffold }\end{array}$ & Crosslinking & $\begin{array}{l}\text { Stimuli } \\
\text { effect }\end{array}$ & Fabrication & Property & Outcome & References \\
\hline & ASCs & Aloe vera hydrogel & & & Injection & & $\begin{array}{l}\text { Improved } \\
\text { angiogenesis and re- } \\
\text { epithelialization, } \\
\text { subsided } \\
\text { inflammation and } \\
\text { scar formation }\end{array}$ & $\begin{array}{l}\text { Oryan et al. } \\
(2019)\end{array}$ \\
\hline & HUCPVC & $\begin{array}{l}\text { Decellularized dermal } \\
\text { matrix }\end{array}$ & & & $\begin{array}{l}\text { Bulk } \\
\text { hydrogel }\end{array}$ & & $\begin{array}{l}\text { Improved VEGFR-2 } \\
\text { expression and } \\
\text { vascular density }\end{array}$ & $\begin{array}{l}\text { Milan et al. } \\
(2016)\end{array}$ \\
\hline & $\begin{array}{l}\text { Dermal } \\
\text { fibroblasts }\end{array}$ & Gelatin & $\begin{array}{l}\text { Catechol } \\
\text { crosslinking } \\
\text { by HRP }\end{array}$ & & $\begin{array}{l}\text { In situ } \\
\text { gelation after } \\
\text { injection }\end{array}$ & & $\begin{array}{l}\text { Facilitated cell } \\
\text { survival and } \\
\text { retention, promoted } \\
\text { mature collagen } \\
\text { deposition and } \\
\text { vascularization }\end{array}$ & $\begin{array}{l}\text { Lee et al. } \\
\text { (2014) }\end{array}$ \\
\hline & $\begin{array}{l}\text { Fibroblasts } \\
\text { and insulin }\end{array}$ & $\begin{array}{l}\text { Poly(vinyl alcohol), PEG } \\
\text { and CS }\end{array}$ & $\begin{array}{l}\text { Schiff base bond } \\
\text { and } \\
\text { phenylboronate } \\
\text { ester }\end{array}$ & $\begin{array}{l}\mathrm{pH} \text { and } \\
\text { glucose }\end{array}$ & $\begin{array}{l}\text { In situ } \\
\text { gelation }\end{array}$ & & $\begin{array}{l}\text { Promoted } \\
\text { neovascularization } \\
\text { and collagen } \\
\text { deposition }\end{array}$ & $\begin{array}{l}\text { Zhao et al. } \\
\text { (2017a) }\end{array}$ \\
\hline & $\begin{array}{l}\text { Cord Blood- } \\
\text { Endothelial } \\
\text { Colony- } \\
\text { Forming } \\
\text { Cells } \\
\text { (ECFCs) }\end{array}$ & $\begin{array}{l}\text { Hyaluronic Acid } \\
\text { Hydrogels }\end{array}$ & $\begin{array}{l}\text { Thiol-Acrylate } \\
\text { conjugation }\end{array}$ & $\begin{array}{l}\text { MMP- } \\
\text { sensitive }\end{array}$ & $\begin{array}{l}\text { Bulk } \\
\text { hydrogels }\end{array}$ & $\begin{array}{l}\text { Adhesiveness, } \\
\text { degradability }\end{array}$ & $\begin{array}{l}\text { Provided micro- } \\
\text { niches for ECFCs to } \\
\text { form vascular } \\
\text { networks and } \\
\text { integrate with the } \\
\text { host vasculatures. } \\
\text { Improve } \\
\text { angiogenesis and } \\
\text { support healthy } \\
\text { epithelialization. }\end{array}$ & $\begin{array}{l}\text { Hanjaya-Putra } \\
\text { et al. (2013) }\end{array}$ \\
\hline
\end{tabular}

eventually therapeutic cells can be incorporated for providing support in consecutive stages of healing (Table 1). In the subsequent section, we categorize hydrogels based on the functional attribute and working principle.

\section{Effects of Hydrogel Scaffold}

Hydrogels that do not involve incorporation of any antiseptics, antibiotics or biomolecules mainly depends on intrinsic antimicrobial properties of the chemical constituents. For example, quaternary ammonium groups are cationic surfactants that react with the anionic phospholipid membrane of bacteria through electrostatic interactions that result in lysis of bacteria cell. These approaches are quite promising, but they need to be further tested if they are sufficient against chronic infection of the wounds (Maris, 1995; Zhou et al., 2014). The major property of hydrogels is their high-water uptake property; however, some hydrogels govern cell recruitment, phenotype, and activation (Wong et al., 2011; Chen et al., 2015; Lohmann et al., 2017), which are very important properties of the hydrogels considering the persistent inflammatory environment in chronic wounds. A pullulan-collagen hydrogels found to increase recruitment of macrophages in murine excisional wounds (Wong et al., 2011). N-isopropylacrylamide hydrogels have also been shown to be effective for reducing proinflammatory M1 macrophages in full thickness wounds of diabetic mice (Chen et al., 2015). There are also inflammatory chemokines like monocyte chemoattractant protein 1, interleukin-8, macrophage inflammatory protein (MIP)-1 $\alpha$, and MIP-1 $\beta$; PEG and GAG derivative hydrogels have been able to isolate them and lessened wound in diabetic mice (Upadhyay et al., 2014). The bare hydrogels are primitive solutions when it comes to proper wound healing. Though previous studies have found hydrogels to facilitate the wound healing, most of them demonstrated that the anti-inflammatory properties come from the additives such as SEW2871 (Kim and Tabata, 2016), phenolic plant extract (Tran et al., 2011; Gong et al., 2013; Upadhyay et al., 2014; Shukla et al., 2016), honey (Mohd Zohdi et al., 2012), and antimicrobial peptides (Li et al., 2015a; Reyes-Ortega et al., 2015). The SEW2871 acts by favoring recruitment of M2 macrophages in local wound site than other macrophages and rest of the additives mentioned reduce oxidative stress and thus helps in wound healing (Tran et al., 2011; Mohd Zohdi et al., 2012; Gong et al., 2013; Upadhyay et al., 2014; Li et al., 2015a; Reyes-Ortega et al., 2015; Shukla et al., 2016). Hydrogels can also modulate the local inflammatory environment by incorporating antioxidant species in the scaffold for enhanced antioxidant activities (Liu et al., 2020b; Xu et al., 2020; Zhang et al., 2020).

\section{Delivery Vehicle of Biomolecules}

Wound healing is a complex and sequential process that involves various signaling molecules associated with inflammation, 
angiogenesis, and tissue remodeling. In the case of chronic wound healing the balance among these molecules becomes unstable. So, one of the promising hydrogel fabrication strategies is to facilitate the biomolecules within and make up for the imbalance. Various bioactive molecules like fibroblast growth factor (FGF), epithelial growth factor (EGF), keratinocyte growth factor, insulin-like growth factor, stromal cell-derived factor 1, vascular endothelial growth factor (VEGF), and platelet-derived growth factor (PDGF) (Beckert et al., 2005; Beckert et al., 2007; Liu et al., 2007; Huang et al., 2009; Koria et al., 2011; Lao et al., 2012; Freudenberg et al., 2015; Goh et al., 2016; Hajimiri et al., 2016; Huang et al., 2016; Wu et al., 2016; Babavalian et al., 2018; Dong et al., 2018; Shamloo et al., 2018; Wise et al., 2018) have been integrated in hydrogels. These factors play direct role in wound healing through rapid wound closure, enhanced reepithelialization, increased ECM deposition and neo vascularization. Enhanced wound healing is also observed for bioactive reagents like superoxide dismutase (SOD), nitroso glutathione, nitric oxide (NO), interleukins, MIP-3a, metal ions etc. independent of animal model, type of the hydrogel used and dosage of the reagents (Masters et al., 2002; Amadeu et al., 2007; Amadeu et al., 2008; Rabbany et al., 2010; Henderson et al., 2011; Schanuel et al., 2015; Chen et al., 2016; Demirci et al., 2016; Kim and Tabata, 2016; Yoon et al., 2016; Zhu et al., 2016; Kim and Tabata, 2017; Xiao et al., 2017; Champeau et al., 2018; Zhang et al., 2018). Moreover, wound healing is also promoted by the growth factors associated with cell migration (Freudenberg et al., 2015), cell proliferation (Beckert et al., 2005; Beckert et al., 2007; Huang et al., 2009; Koria et al., 2011; Lao et al., 2012; Hajimiri et al., 2016; Huang et al., 2016) etc. Though most of the studies demonstrate some degree of improvement in wound healing, the exact mechanism of such process is still not well understood (Beckert et al., 2007; Koria et al., 2011; Freudenberg et al., 2015; Huang et al., 2016; Wise et al., 2018). One interesting study took a different approach and used release of encoded plasmids for specific growth factors from hydrogels. DNA vector encoded VEGF was used to influence the angiogenesis in diabatic wound, even in the absent of pro angiogenic factor (Tokatlian et al., 2015). Though a better granulation of the tissue was observed, no significant improvement on angiogenesis was shown. Platelet rich plasma (PRP) is also shown to be effective in wound healing process, where the PRP releasing hydrogels works better than treatment with PRP only (Notodihardjo et al., 2015; Houdek et al., 2016; Qiu et al., 2016; Park et al., 2017).

\section{Cell Based Hydrogels}

\section{The Roles of Stem Cells in Wound Healing}

A critical problem of using stem cells in wound healing is the retention time of the transplanted stem cells within the wound beds. Hydrogels are very useful in this aspect considering that they increase the residual time for the stem cells in the wound (Natesan et al., 2013; Xu et al., 2013; Garg et al., 2014; Chen et al., 2015; Kim et al., 2016; Kosaraju et al., 2016; Cheng et al., 2017; da Silva et al., 2017; Kaisang et al., 2017; Dong et al., 2018; Lei et al., 2018; Shou et al., 2018; Xu et al., 2018; Hsu et al., 2019). In general, this is possible due to hydrogels being the promoter of the cell adhesion and acting as a medium for maintaining the proper phenotype of the cells (Seliktar, 2012; Rice et al., 2013; da Silva et al., 2016). This homing property is improved by pre-culturing the stem cells in hydrogels in vitro, as some studies have shown extended period of cell dwelling time in the wound up to 11 days post transplantation (Rustad et al., 2012; Zeng et al., 2015). There are also different approaches in using stem cells, as some studies leverage debatable differentiation of the stem cells into skin lineages (Rustad et al., 2012; Zeng et al., 2015) and some studies focus on the therapeutic potential of undifferentiated stem cells (Chamberlain et al., 2007). The undifferentiated stem cell can contribute to the enhanced immunoregulatory capacity (Xu et al., 2013; Chen et al., 2015; Shou et al., 2018; Xu et al., 2018; Hsu et al., 2019), regenerative secretome release (Garg et al., 2014; Chen et al., 2015; Choi et al., 2016; Cheng et al., 2017; Kaisang et al., 2017; Skardal et al., 2017; Lei et al., 2018; Xu et al., 2018), angiogenesis (Rustad et al., 2012; Natesan et al., 2013; Xu et al., 2013; Garg et al., 2014; Chen et al., 2015; Zeng et al., 2015; Choi et al., 2016; Kim et al., 2016; Kosaraju et al., 2016; Kaisang et al., 2017; Skardal et al., 2017; Dong et al., 2018; Shou et al., 2018; Hsu et al., 2019) and cell recruiting potential (Natesan et al., 2013; Kosaraju et al., 2016; Lei et al., 2018). So far, the most contributing effect of the stem cell-based hydrogel is formation of new vessel in critically impaired wounds (Rustad et al., 2012; Natesan et al., 2013; Xu et al., 2013; Garg et al., 2014; Chen et al., 2015; Zeng et al., 2015; Choi et al., 2016; Kim et al., 2016; Kosaraju et al., 2016; da Silva et al., 2017; Kaisang et al., 2017; Skardal et al., 2017; Dong et al., 2018; Shou et al., 2018; Xu et al., 2018; Hsu et al., 2019); nonetheless, other features mentioned earlier can also play significant roles in wound healing especially in case of chronic wounds. Capacity to release high level of angiogenic factors (Garg et al., 2014; Choi et al., 2016; Cheng et al., 2017; Kaisang et al., 2017; Skardal et al., 2017; Lei et al., 2018; Xu et al., 2018) and recruit circulating progenitor cells (Kosaraju et al., 2016) indicate that stem cell laden hydrogels can provide an angiogenic environment. Furthermore, secretome release supposedly also improves epithelialization of diabetic excisional wounds but increased levels of FGF, TGF betal and EGF detected in vitro are not substantially present in in vivo environment of wound (Chen et al., 2015). Reduced levels of immune cells like macrophages, $\mathrm{T}$ lymphocytes, polymorphonuclear cells, and mononuclear cells (da Silva et al., 2017; Dong et al., 2018; Shou et al., 2018), a higher ratio of anti-inflammatory to proinflammatory (M2/M1) macrophages (da Silva et al., 2017), and reduced levels of inflammatory mediators (i.e., TNFa) (Xu et al., 2018) have also been detected in wounds while treated with stem cell-laden hydrogels. Thus, it is apparent stem cell laden Hydrogels contribute to all stage of wound healing profoundly and has better therapeutic potential compared to providing only biomolecules.

\section{Endothelial Cell-Based Therapy}

Though stem cell-based hydrogel has better all-round potential in wound healing, it fails to provide specialized rapid response in chronic case like ischemia and impaired angiogenesis, where loss of tissue viability and necrosis is apparent (Armstrong et al., 2007; Barrientos et al., 2008). Well networked capillaries and better blood perfusion is critical in these scenarios. Collagen 
(Biedermann et al., 2014; Klar et al., 2016; Brett et al., 2017; Skardal et al., 2017), fibrin (Skardal et al., 2017) and hyaluronic acid-based (Davis and Senger, 2005; Ibrahim and Ramamurthi, 2008; Cerqueira et al., 2014; Shen et al., 2016) hydrogels have natural angiogenic features and in some cases also provide binding site for endothelial cell receptors (Yee et al., 2011). These characteristics make them better suitable for to use in combination with endothelial progenitor cells, such as endothelial colony-forming cells (Hanjaya-Putra et al., 2011; Hanjaya-Putra et al., 2012). For inducing faster vessel formation, the prevascularized constructs can be prepared in vitro, and implanted into the wound beds (Hanjaya-Putra et al., 2013). Endothelial colony forming cells (ECFCs) can be combined with pericytes and fibroblasts within the hydrogels to form vascularized hydrogels with functional skin and hair tissues (Moon et al., 2010; Ali et al., 2013; Chwalek et al., 2014; Mohandas et al., 2015b; Sun et al., 2016; Abaci et al., 2018). One such prevascularized hydrogel is reported where endothelial cells derived from adipose stromal vascular fraction is cultured in fibrin-collagen type I. Upon transplantation into wounds in immunodeficient rats, host vasculature is observed in only 4 days (Klar et al., 2016).

Similarly, human induced pluripotent stem cells (hiPSC) derived early vascular cells from patient as well as healthy donor has showed the capacity to prevascularize hyaluronic acid hydrogels (Kusuma et al., 2013). The application of such hydrogels has shown to improve not only vascularization and blood perfusion but also macrophage infiltration in hydrogel, accelerated wound closure, granulation in diabetic rats (Shen et al., 2016). It is notable that, the CD248 expressing cell within stromal vascular fraction shows high level of angiogenic gene transcripts. When applied in conjunction with pullulan-collagen gels, exhibited faster re-epithelialization and vascularization in mice (Brett et al., 2017). Similar results have been reported using gum-hyaluronic acid hydrogels incorporated with human adipose-derived stem cells (hASCs) and microvascular endothelial cells (Cerqueira et al., 2014).

\section{Schwann Cell-Based Therapy}

Cutaneous peripheral nervous system is very much important in prompting the release of neuropeptides and neurotrophic factors that regulate many aspects of healing mechanisms (Laverdet et al., 2015), but its regeneration during wound healing is not much focused in recent studies. In many cases, neuropathic skin is associated with impaired healing of chronic wounds, it goes without saying that regeneration of damaged nerves and neuromodulator levels are of considerable importance. Schwann cells are major component in the treatment of neuropathy as they are in control of nerve repair (Jessen et al., 2015). One such research incorporates mouse Schwann cells into human tissue engineered skin substitute. The results show enhanced nerve fiber migration and myelin sheath formation which led to a recovery of nerve function in some degree (Blais et al., 2009). Despite this early promising result, utilization of human Schwann cells has not been made possible for clinical applications as isolation and expansion of human Schwann cells is very much challenging. Even differentiation from dermal skin derived precursor (Hill et al., 2012) or from hiPSCs (Tomita et al., 2013) remain a difficult task. As a matter of fact, differentiated hASCs exhibiting schwann cell like phenotype, incorporated in hyaluronic acid-based hydrogel failed to promote nerve generation in diabetic mice (da Silva et al., 2017). Some studies on the other hand shows direct effect of neuromediators on inflammatory cytokine expression, which might pave way for future research to promote nerve regeneration within chronic wounds (Moura et al., 2014; Kant et al., 2015).

\section{POTENTIAL OF HYDROGELS IN SPECIFIC CHRONIC WOUND HEALING}

Compared to acute wound, chronic wound usually stays in the inflammatory phase due to the imbalance of ROS, protease, inflammatory cytokines, senescent cells and results in persistent infections which is difficult to heal in an orderly manner. The high expression of protease exceeds their inhibitors result in degradation of growth factors and their receptors and extracellular matrix (ECM). Chang et al. identified up-regulation of active-matrix metalloproteinase- 9 (MMP-9) in diabetic wounds and validated it as a novel therapeutic target for diabetic wound treatment (Nguyen et al., 2018). They found a highly selective MMP-9 inhibitor, $(R)-\mathrm{ND}$ 336 that can restore the normal wound healing process without MMP-8 inhibition. The combinatorial topical administration of (R)-ND-336 with active MMP-8 (Gao et al., 2015) or linezolid (Peng et al., 2021) significantly accelerated diabetic wound healing. Due to the repeated tissue injury, immune cells are accumulated, leading to proinflammatory cytokines cascade amplification which in turn gives rise to prolong inflammatory response. The transformation from proinflammatory macrophages (M1) to anti-inflammatory macrophages (M2) is hindered in case of delayed wound healing (den Dekker et al., 2019; Kim et al., 2019; Umehara et al., 2019). On the other hand, excessive ECM degradation intensifies the inflammatory response.

In chronic wounds, ROS is much higher than normal wounds, which can perturb the balance of cell redox state as well as the balance of protease and its inhibitors resulting in further ECM degradation and premature cell failure (Huang et al., 2019; Kathawala et al., 2019; Xian et al., 2020). In diabetic wounds, high blood glucose is an inevitable factor. It is connected to delayed wound healing through decreasing macrophages (Maruyama et al., 2007), increasing oxidative stress (Dai et al., 2019) and glycation of proteins, and favoring bacterial infection. Glycation of protein is detrimental to blood vessel formation, cell proliferation and differentiation. Lack of angiogenesis decreases the oxygen and nutrients supply, thus retarding tissue regeneration and wound healing. It is found that decrease in heparin sulfate proteoglycans disturb the regulation of growth factors (Das et al., 2016; Monteforte et al., 2016). Therefore, delivery of added growth factors is beneficial for wound healing. Bacterial infection plays an important role in chronic wound healing. Open wound tissue with excess extrude is easy for 


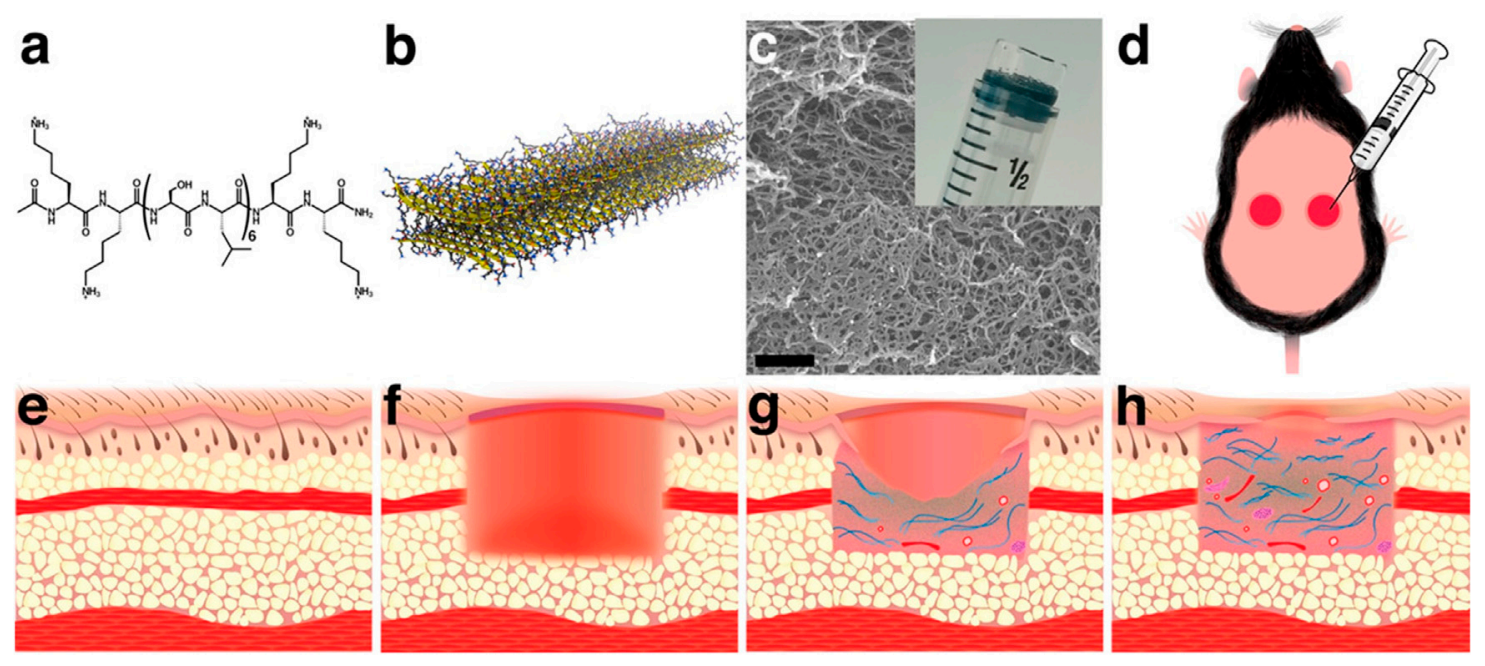

FIGURE 7 | Multidomain peptide (MDP) forms a nanofibrous hydrogel that is easily applied to wounds in a diabetic mouse model. (A) 16-amino acid MDP, K2(SL) $6 K 2$, forms (B) nanofibers through the hydrophobic effect and hydrogen bonding. (C) Nanofibers cross-link with multivalent salts to form a hydrogel. (D) Because the hydrogel is syringe deliverable, it can be easily applied to wounds and conforms to their shape. (E) Before creation of the wound, the subcutaneous tissue is filled with adipose tissue and the panniculus carnosus muscle layer. (F) Wounding of the dorsal tissue removes epithelium, adipose tissue, and the panniculus carnosus. (G) As the wound heals granulation tissue, collagen, blood vessels, and neural fascicles fill the wound bed and epithelial cells migrate across the granulation tissue creating epithelial tongues. (H) Over time, the amount of granulation tissue, collagen, blood vessels, and neural fascicles increase, and the epithelial tongues extend to close the wound (Carrejo et al., 2018). Images were adapted with permission from Carrejo et al. (2018). Copyright 2018, American Chemical Society.

bacterial settling and breeding which can cause continuous inflammation. The wash step of wound before wrapping with wound dressing is to roughly prevent infections. Thus, eradicating bacteria is essential for hydrogel wound dressing. In some cases, encapsulation of antibacterial reagent is needed. Therefore, hydrogel dressings should be designed based on the specific properties of chronic wounds.

\section{Diabetic Wounds}

Diabetic wounds are significant complications of diabetes with high recurrence and amputation rate. Currently, the treatment options are limited and ineffective. Hydrogel provides a promising platform manifested by versatile engineering to endow various biofunctions to promote diabetic wound healing. In addition to traditional polymers for hydrogel preparation, multidomain peptide (MDP) is a promising material, as it allows rapid cell infiltration and elicit a mild inflammatory response which promotes angiogenesis. Hartgerink et al. (Carrejo et al., 2018) investigated the effect of MDP hydrogel on full-thickness diabetic wounds (Figure 7). They found that the MDP hydrogel can increase wound contraction by granulation tissue and re-epithelialization without the addition of exogenous growth factors or cells.

To improve therapeutic effects of hydrogels, a series of therapeutic reagents are encapsulated. In diabetic wounds, MMP-9 is highly expressed thus impede wound healing. Yao et al. (Sonamuthu et al., 2020) prepared metal chelating dipeptide (L-carnosine) hydrogel with antibacterial Cur to inactivate MMP9 by chelation between $\mathrm{Zn}(\mathrm{II})$ and L-carnosine. The combinatorial effects of MMP-9 inactivation and bacterial inhibition alleviated the diabetic wound. The wound healing needs supply of oxygen, nutrients, and cell factors which is highly dependent on vascular system. Therefore, promoting revascularization is crucial for diabetic wound healing. Peptide KLTWQELYQLKYKGI was found to mimic VEGF bioactivity. Conjugation of this peptide with peptide amphiphile molecules afforded supramolecular peptide nanostructures with proangiogenic behavior (Webber et al., 2011; Kumar et al., 2015). Segura et al. (Tokatlian et al., 2015) prepared gene delivery hydrogel for encapsulated reporter (pGFPluc) or proangiogenic (pVEGF) plasmids to promote angiogenesis. Si ions in bioglass (BG) can upregulate VEGF expression to promote angiogenesis. He et al. (Kong et al., 2018) fabricated injectable hydrogel to deliver BG and desferrioxamine (DFO), a natural hydrophilic product which can promotes the secretion of VEGF and stromal cell derived factor 1 . The hydrogel showed synergistic effects on promoting VEGF expression and angiogenesis leading to enhanced diabetic wound healing. Lin et al. (Liu et al., 2019) investigated recombinant human fibroblast growth factor 21 (rhFGF21) hydrogel consist of heparin and poloxamer. The release of rhFGF21 was controlled by heparin in a sustained manner. The hydrogel significantly improved wound closure through promoting granulation, collagen deposition, and reepithelialization.

Cell based therapeutic intervention have attracted much more attention for wound healing due to the inherent regenerative ability and reduced scar forming. Multipotent mesenchymal stromal cells (MSCs) are the main source for cell-based hydrogel dressing. Injectable hydrogel via thiol-ene Michael type addition were fabricated for hASCs delivery (Dong et al., 2018; Xu et al., 2018). These hydrogels increased ASCs retention while retaining viability, stemness, proliferation, and metabolic 
activity up to 3 weeks. The results showed accelerated diabetic wound healing through deceasing inflammation, proangiogenesis and promoting re-epithelialization. Acellular dermal matrix maintains the properties of natural extracellular matrix which are advantageous for MSCs based therapy. Acellular dermal matrix hydrogel significantly enhanced tissue regeneration and neovascularization resulted in accelerated wound healing (Nie et al., 2015). Bone marrow mesenchymal stem cells (BMSCs) hydrogel was investigated by Zhang et al. (Chen et al., 2015) with synthetic polymers. The BMSCs hydrogel showed anti-inflammatory activity and accelerated wound healing by a series of paracrine growth factors (TGF- $\beta 1$, FGF). Currently, most of MSCs are prepared by invasive procurement procedures. Samadikuchaksaraei et al. (Milan et al., 2016) confirmed human umbilical cord perivascular cells (HUCPVCs) is an alternative source of MSCs for diabetic wound healing due to the higher proliferative rate and better frequency.

\section{Infected Wounds}

Antibiotics are widely used antibacterial drugs; antibiotics encapsulation is a straightforward way to prepare antibacterial hydrogels. Dual delivery of antibiotics and growth factors, such as co-delivery of vancomycin and VEGF (Huang et al., 2018a) or codelivery of ampicillin or lincomycin and basic fibroblast growth factor (FGF-2) (Cui et al., 2020) with hydrogels were studied to inhibit bacterial and accelerate skin cell proliferation. One concern about antibiotics delivery is the increase in bacterial resistance. Some cations can bind to negatively charged bacterial membranes and subsequently kill bacteria by destroying the membranes. Octenidine (Oct) is a broad-spectrum antiseptic agent with no resistance so far. Codelivery of Oct and chitosan-treated serum (CTS) accelerated infected wound healing via bacterial clearance and neutrophilic attraction (Muthuswamy et al., 2019). Similar to Oct, dodecyl moiety (Chen et al., 2018) was modified onto hydrogel to inhibit bacterial by anchoring and destructing bacterial membrane. Nitric acid (NO) exerts broad-spectrum antibacterial effect through the formation of reactive nitrogen species. A NO releasing hydrogel was fabricated by encapsulating S-nitrosoglutathione (GSNO) (Lee et al., 2019) which can release NO under physiological conditions. To minimize drug resistance, photodynamic therapy is developed to produce heat or ROS leading to irreversible damage and bacterial death. Porphyrin photosensitizer sinoporphyrin sodium (DVDMS) containing hydrogel showed excellent antibacterial and antibiofilm activities under mild photoirradiation (Mai et al., 2020). Graphene oxide (GO) possess excellent photothermal properties, embedding GO into antibacterial quaternized chitosan hydrogel demonstrated enhanced infected wound healing (Liang et al., 2020). PDA NPs in reduced state have been confirmed as a ROS-donating and photothermal material. PDA NPs containing hydrogel (Sun et al., 2020) showed synergistic antibacterial activity based on ROS releasing and NIR-photothermal effects.

Silver ion and silver nanoparticles (Ag NPs) is widely used in hydrogel for antibacterial property. Antibacterial silver and basic fibroblast growth factor (bFGF) delivery hydrogel was prepared by $\mathrm{Wu}$ et al. (Xuan et al., 2020) with silver act as a crosslinker. The combinatorial effects of bacterial inhibition and accelerated cell proliferation and migration reversed impaired wound healing process. By introducing vascularization promoting polypeptide through S-Ag coordination bonds (Figure 8A), the silver ion containing hydrogel showed synergetic antibacterial and vascularization abilities to promote infected wound healing. Copper ion and copper nanoparticles ( $\mathrm{Cu}$ NPs) also possess ROS induction and photothermal property. NIR laser irradiation $(808 \mathrm{~nm})$ of $\mathrm{Cu}$ NPs encapsulated hydrogel can effectively produce heat locally and ROS to kill bacteria (Tao et al., 2019). Qu et al. (Qiu et al., 2020) reported that peroxidaselike activity of copper ion crosslinked hydrogel (Figure 8B) could convert $\mathrm{H}_{2} \mathrm{O}_{2}$ into ROS at low $\mathrm{H}_{2} \mathrm{O}_{2}$ level which resulted in excellent bacterial termination to accelerate infected wound healing.

A living hydrogel of microalgae Spirulina platensis (SP) with carboxymethyl chitosan was reported by Zhou et al. (Li et al., 2021 ) to accelerate infected wound healing. The chlorophyll in SP releases oxygen continuously under illumination to alleviate hypoxia, decrease ROS production and effectively eliminate bacteria.

\section{Burn Wounds}

Burn injuries lead to necrotic tissue formation followed by inflammatory response and coagulation process, resulted in delayed wound healing. Hydrogel is beneficial for burn wound to absorb excess exudes and keep a moist microenvironment; especially injectable hydrogel is easy for administration to cover the wound completely without pain. Chen et al. (Li et al., 2015b) utilizing Schiff base crosslinking between amino groups of carboxymethyl chitosan (CMC) and aldehyde groups of oxidized dextran (Odex) prepared injectable hydrogel. They found the cell attachment is increased with higher CMC content. The hydrogel displayed good cytocompatibility and accelerated burn wound healing. Applying the same crosslinking mechanism, Zhang et al. (Huang et al., 2018b) fabricated injectable hydrogel with CMC and rigid rod-like dialdehyde-modified cellulose nanocrystal (DACNC). The hydrogel was able to speed deep partial thickness burn wound healing and resolve pains during wound dressing changes with glycine. Dhara et al. (Bankoti et al., 2020b) constructed injectable hydrogel through blending extracted acellular dermal matrix from full thickness skin with chitosan. This hydrogel preserved innate biological composition, ultrastructure with enhanced mechanical properties and demonstrated rapid full thickness burn wound healing.

Injectable hydrogel for burn wound healing with active therapeutic reagents may favor versatile functions under various conditions. It is also important to prevent bacterial infection for burn wound. Ag NPs are widely used for antibacterial hydrogel preparation. Park et al. (Kim et al., 2018) explored in situ formation of Ag NPs for antibacterial hydrogel construction with thermo-sensitive methylcellulose (MC). The Ag NPs thermo-responsive hydrogel demonstrated 

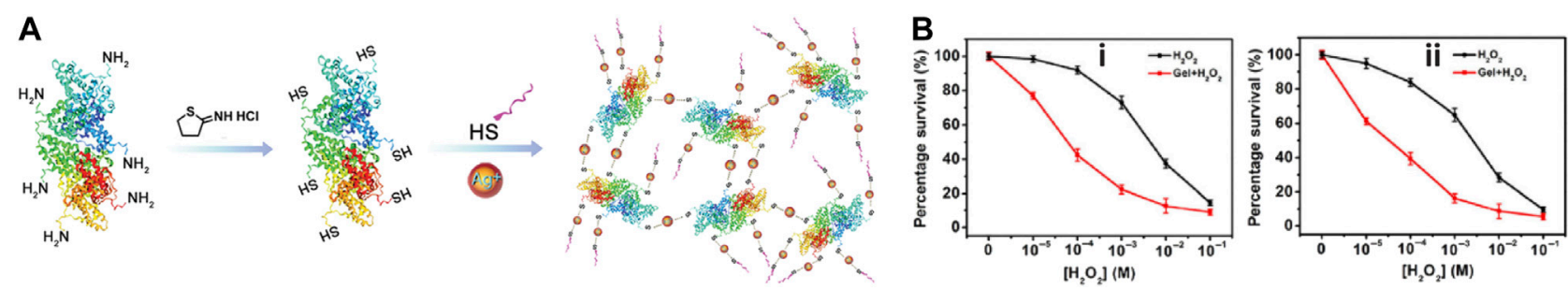

FIGURE 8 | (A) S-Ag coordination bonds between thiolated bovine serum albumin (BSA-SH), thiolated polypeptide (KK-SH), and Ag ${ }^{+}$to form hydrogel (Cheng et al., 2020). Images were adapted with permission from Cheng et al. (2020). Copyright 2020, John Wiley and Sons. (B) With copper ion as peroxidase-like agent, hydrogel crosslinked with copper ion significantly deceased survival rates of DR- S. aureus (i) and DR- E. coli (ii) (Qiu et al., 2020). Images were adapted with permission from Qiu et al. (2020). Copyright 2020, Springer Nature.
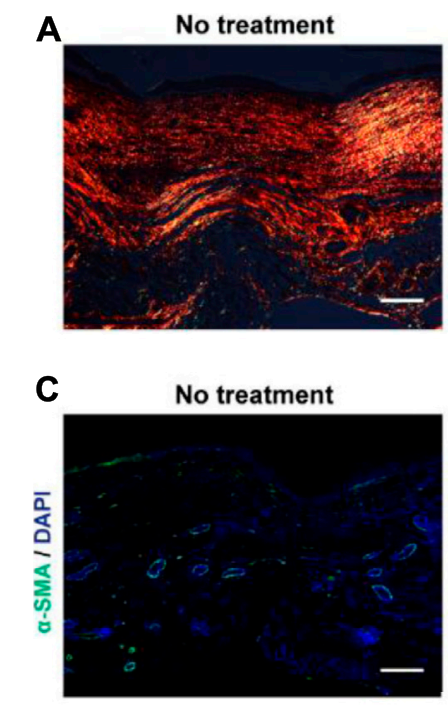
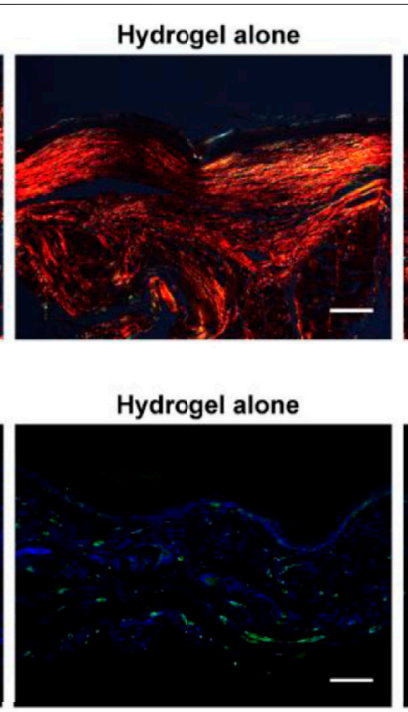

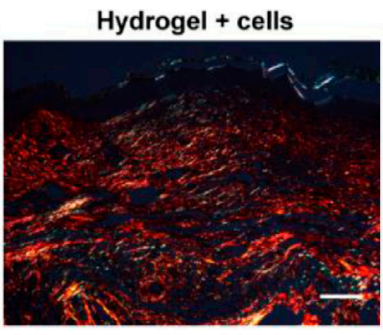

Hydrogel + cells

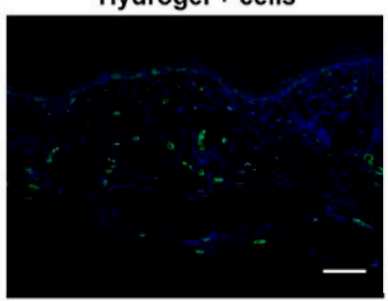

B

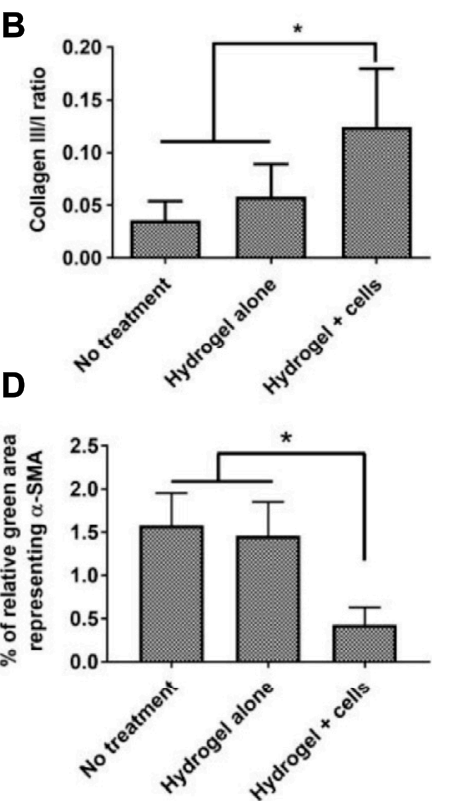

FIGURE 9 | Effects of the PEG-HA-RGD hydrogel-ASC treatment on tissue remodeling and scar formation. (A) Collagen deposition of the wounded area was assessed by polarized light microscopy with picrosirius red staining. (B) The ratio of collagen type III/I is significantly higher in "hydrogel + cells" treatment compared to the control groups. (C) Representative fluorescent images of $\alpha-S M A^{+}$stained cells in healed wounds. (D) Quantified result demonstrates the hydrogel-ASC treatment significantly decreases representing a-SMA positive myofibroblasts in healed wounds (Dong et al., 2020). Images were adapted with permission from Dong et al. (2020). Copyright 2020, Elsevier.

excellent antibacterial activity and promoted burn wound healing. Colistin is a clinical applied lipopeptide with antibacterial activity. However, this peptide possesses nephrotoxicity. Localized delivery with hydrogels can reduce the toxicity. After incorporated into hydrogel, it showed similar activity as native colistin (Zhu et al., 2017). Cur has broad spectrum of functionalities including anti-inflammatory, antibacterial and anti-oxidation activities. To improve bioavailability and overcome solubility of Cur, nano-sized Cur was synthesized and encapsulated into thermo-responsive pluronic-grafted gelatin hydrogel (Dang et al., 2019). The nanocomposite hydrogel showed sustained Cur release and enhanced second-degree burn wound healing. Excessive inflammation and lack of angiogenesis impair the burn wound healing. Resveratrol (Res) was delivered with injectable hydrogel through supramolecular interaction. Combining with VEGF plasmid (Wang et al., 2019c) or histatin-1 (Zheng et al., 2020) delivery, inhibition of inflammatory response and acceleration of vascularization were achieved to improve wound healing.

MSCs have been widely used in treating wounds. MSCs are beneficial to modulate immune response, secrete cytokines and growth factors, thus provide building blocks for tissue regeneration with reduce hypertrophic scarring. Gurtner et al. (Dong et al., 2020) delivered adipose-derived stem cells (ASCs) to burn wounds with hyaluronic acid hydrogel. The hydrogel-ASC treatment significantly promoted angiogenesis, accelerated wound closure and reduced the scar formation (Figure 9). With Aloe vera hydrogel as a carrier, ASCs subsided the 
inflammatory responses, enhanced angiogenesis, and reepithelialization, thereby accelerated burn wound healing (Oryan et al., 2019). The major advantage of ASCs delivery is decrease in scar formation by alleviating myofibroblast activities and collagen deposition. ASC is also significant to restore normal skin functions as well as nice appearance.

\section{CONCLUSION}

Wound management has attracted significant interest in view of the broad demand market. Among the various available dressing materials, hydrogels have drawn increasing attention for their tunable chemical, physical and biological properties. Hydrogels have shown to have significant outcome and play important role in treating wounds. Recent advancements in hydrogel synthesis have enabled scientists to incorporate many of the physicochemical properties of human tissue and thus facilitating better tissue regeneration. Despite of the recent improvement, more effort should be given on the fabrication of hydrogel through new chemical and physical crosslinking, perhaps combination of both to mimic more of in vivo dynamic behavior. To further expand the scope of hydrogel applications, new routes for click chemistry, enzymatic reactions, crystallizations, and amphiphilic block co-polymers need to be explored. Moreover, design structure, effective energy dissipation etc. should also be optimized to extend the effectiveness of hydrogels. In parallel to synthetic polymers, structural modification of the natural polymers will also be a significant step as structural limitations of hydrogel remain one of the hurdles to date. More green and efficient hydrogel preparations processes are expected for clinical translation. Successful injectable or sprayable hydrogel can drive all these collected efforts one step further. Moreover, smart hydrogel based wound dressing integrated with sensors are also being conceptualized to deliver real time information about the wound healing process.

To date, hydrogel-based strategies developed for the treatment of skin wounds have presented many challenges, at the same time new opportunities. Each chronic wound has a different condition that needs to be recognized as unique and has to be prioritized as a prerequisite for targeting the wound's particular pathophysiology.

\section{REFERENCES}

Abaci, H. E., Coffman, A., Doucet, Y., Chen, J., Jacków, J., Wang, E., et al. (2018). Tissue Engineering of Human Hair Follicles Using a Biomimetic Developmental Approach. Nat. Commun. 9, 1-11. doi:10.1038/s41467-018-07579-y

Ahmed, S., and Ikram, S. (2016). Chitosan Based Scaffolds and Their Applications in Wound Healing. Achievements Life Sci. 10, 27-37. doi:10.1016/ j.als.2016.04.001

Ali, S., Saik, J. E., Gould, D. J., Dickinson, M. E., and West, J. L. (2013). Immobilization of Cell-Adhesive Laminin Peptides in Degradable PEGDA Hydrogels Influences Endothelial Cell Tubulogenesis. Bioresearch Open Access 2, 241-249. doi:10.1089/biores.2013.0021

Amadeu, T. P., Seabra, A. B., de Oliveira, M. G., and Costa, A. M. A. (2007). S-nitrosoglutathione-containing Hydrogel Accelerates Rat Cutaneous Wound Repair. J. Eur. Acad. Dermatol. Venereol. 21, 629-637. doi:10.1111/j.14683083.2006.02032.x
Tailor-made therapies have already been adopted for different types of acute wounds and will become increasingly relevant for chronic wounds in coming days. Though, hydrogels are predicted to replace conventional wound dressing in future, number of clinically approved hydrogels in the market is still not satisfactory. More clinical trials and relevant in vivo studies will help us realize the broad commercial use of hydrogel with costeffectiveness and ease of use.

\section{DATA AVAILABILITY STATEMENT}

The original contributions presented in the study are included in the article/supplementary material, further inquiries can be directed to the corresponding author.

\section{AUTHOR CONTRIBUTIONS}

FF reviewed the use of hydrogels for wound healing and drafted the manuscript. SS reviewed the use of stem cells for wound healing and drafted the manuscript. DH-P outlined and edited the manuscript. All authors read and approved the final manuscript.

\section{FUNDING}

ACS IRG-17-182-04 19-CDA-34630012 NIH ULITR001108 NSF-CBET-2047903.

\section{ACKNOWLEDGMENTS}

We acknowledge support from the University of Notre Dame through “Advancing Our Vision” Initiative in Stem Cell Research, Harper Cancer Research Institute - American Cancer Society Institutional Research Grant (IRG-17-182-04), American Heart Association through Career Development Award (19-CDA34630012 to DH-P), and from National Institutes of Health (1R35-GM-143055-01 to DH-P).

Amadeu, T. P., Seabra, A. B., de Oliveira, M. G., and Monte-Alto-Costa, A. (2008). Nitric Oxide Donor Improves Healing if Applied on Inflammatory and Proliferative Phase. J. Surg. Res. 149, 84-93. doi:10.1016/j.jss.2007.10.015

Amato, G., Grimaudo, M. A., Alvarez-Lorenzo, C., Concheiro, A., Carbone, C., Bonaccorso, A., et al. (2020). Hyaluronan/Poly-L-lysine/Berberine Nanogels for Impaired Wound Healing. Pharmaceutics 13, 34. doi:10.3390/ pharmaceutics 13010034

Annabi, N., Rana, D., Shirzaei Sani, E., Portillo-Lara, R., Gifford, J. L., Fares, M. M., et al. (2017). Engineering a Sprayable and Elastic Hydrogel Adhesive with Antimicrobial Properties for Wound Healing. Biomaterials 139, 229-243. doi:10.1016/j.biomaterials.2017.05.011

Arkenberg, M. R., Moore, D. M., and Lin, C.-C. (2019). Dynamic Control of Hydrogel Crosslinking via Sortase-Mediated Reversible Transpeptidation. Acta Biomater. 83, 83-95. doi:10.1016/j.actbio.2018.11.011

Armstrong, D. G., Wrobel, J., and Robbins, J. M. (2007). Guest Editorial: Are Diabetes-Related Wounds and Amputations Worse Than Cancer?. Int. Wound J. 4, 286-287. doi:10.1111/j.1742-481X.2007.00392.x 
Ashoori, Y., Mohkam, M., Heidari, R., Abootalebi, S. N., Mousavi, S. M., Hashemi, S. A., et al. (2020). Development and In Vivo Characterization of Probiotic Lysate-Treated Chitosan Nanogel as a Novel Biocompatible Formulation for Wound Healing. Biomed. Res. Int. 2020, 1-9. doi: $10.1155 / 2020 / 8868618$

Babavalian, H., Tebyanian, H., Latifi, A. M., Shokrgozar, M. A., Bonakdar, S., and Shakeri, F. (2018). The Effect of Synthetic Alginate Sulfate Hydrogels with Recombinant PDGF-BB on Wound Healing. Bll 119, 391-396. doi:10.4149/ bll_2018_072

Bahadoran, M., Shamloo, A., and Nokoorani, Y. D. (2020). Development of a Polyvinyl Alcohol/sodium Alginate Hydrogel-Based Scaffold Incorporating bFGF-Encapsulated Microspheres for Accelerated Wound Healing. Sci. Rep. 10, 1. doi:10.1038/s41598-020-64480-9

Bankoti, K., Rameshbabu, A. P., Datta, S., Goswami, P., Roy, M., Das, D., et al. (2020). Dual Functionalized Injectable Hybrid Extracellular Matrix Hydrogel for Burn Wounds. Biomacromolecules 22, 514-533. doi:10.1021/ acs.biomac.0c01400

Bankoti, K., Rameshbabu, A. P., Datta, S., Roy, M., Goswami, P., Roy, S., et al. (2020). Carbon Nanodot Decorated Acellular Dermal Matrix Hydrogel Augments Chronic Wound Closure. J. Mater. Chem. B 8, 9277-9294. doi:10.1039/d0tb01574a

Barrientos, S., Stojadinovic, O., Golinko, M. S., Brem, H., and Tomic-Canic, M. (2008). Growth Factors and Cytokines in Wound Healing. Wound Repair Regen. 16, 585-601. doi:10.1111/j.1524-475X.2008.00410.x

Beckert, S., Haack, S., Hierlemann, H., Farrahi, F., Mayer, P., Königsrainer, A., et al. (2007). Stimulation of Steroid-Suppressed Cutaneous Healing by Repeated Topical Application of IGF-I: Different Mechanisms of Action Based upon the Mode of IGF-I Delivery. J. Surg. Res. 139, 217-221. doi:10.1016/ j.jss.2006.08.006

Beckert, S., Hierlemann, H., Muschenborn, N., Witte, M., Ranke, M., and Coerper, S. (2005). Experimental Ischemic Wounds: Correlation of Cell Proliferation and Insulin-like Growth Factor I Expression and its Modification by Different Local IGF-I Release Systems. Wound Repair Regen. 13, 278-283. doi:10.1111/j.10671927.2005.130310.x

Biedermann, T., Klar, A. S., Böttcher-Haberzeth, S., Schiestl, C., Reichmann, E., and Meuli, M. (2014). Tissue-engineered Dermo-Epidermal Skin Analogs Exhibit De Novo Formation of a Near Natural Neurovascular Link 10 Weeks after Transplantation. Pediatr. Surg. Int. 30, 165-172. doi:10.1007/s00383-0133446-x

Blais, M., Grenier, M., and Berthod, F. (2009). Improvement of Nerve Regeneration in Tissue-Engineered Skin Enriched with Schwann Cells. J. Invest. Dermatol. 129, 2895-2900. doi:10.1038/jid.2009.159

Brett, E., Zielins, E. R., Chin, M., Januszyk, M., Blackshear, C. P., Findlay, M., et al. (2017). Isolation of CD248-Expressing Stromal Vascular Fraction for Targeted Improvement of Wound Healing. Wound Rep. Reg. 25, 414-422. doi:10.1111/ wrr. 12542

Broguiere, N., Formica, F. A., Barreto, G., and Zenobi-Wong, M. (2018). Sortase A as a Cross-Linking Enzyme in Tissue Engineering. Acta Biomater. 77, 182-190. doi:10.1016/j.actbio.2018.07.020

Carrejo, N. C., Moore, A. N., Lopez Silva, T. L., Leach, D. G., Li, I.-C., Walker, D. R., et al. (2018). Multidomain Peptide Hydrogel Accelerates Healing of FullThickness Wounds in Diabetic Mice. ACS Biomater. Sci. Eng. 4, 1386-1396. doi:10.1021/acsbiomaterials.8b00031

Cerqueira, M. T., da Silva, L. P., Santos, T. C., Pirraco, R. P., Correlo, V. M., Reis, R. L., et al. (2014). Gellan Gum-Hyaluronic Acid Spongy-like Hydrogels and Cells from Adipose Tissue Synergize Promoting Neoskin Vascularization. ACS Appl. Mater. Inter. 6, 19668-19679. doi:10.1021/am504520j

Chamberlain, G., Fox, J., Ashton, B., and Middleton, J. (2007). Concise Review: Mesenchymal Stem Cells: Their Phenotype, Differentiation Capacity, Immunological Features, and Potential for Homing. Stem Cells 25, 2739-2749. doi:10.1634/stemcells.2007-0197

Champeau, M., Póvoa, V., Militão, L., Cabrini, F. M., Picheth, G. F., Meneau, F., et al. (2018). Supramolecular Poly(acrylic acid)/F127 Hydrogel with HydrationControlled Nitric Oxide Release for Enhancing Wound Healing. Acta Biomater. 74, 312-325. doi:10.1016/j.actbio.2018.05.025

Chang, M. (2016). Restructuring of the Extracellular Matrix in Diabetic Wounds and Healing: A Perspective. Pharmacol. Res. 107, 243-248. doi:10.1016/ j.phrs.2016.03.008
Chen, C., Yang, X., Li, S.-j., Zhang, C., Ma, Y.-n., Ma, Y.-x., et al. (2021). Tannic Acid-Thioctic Acid Hydrogel: A Novel Injectable Supramolecular Adhesive Gel for Wound Healing. Green. Chem. 23, 1794-1804. doi:10.1039/d0gc02909b

Chen, G., Yu, Y., Wu, X., Wang, G., Ren, J., and Zhao, Y. (2018). Bioinspired Multifunctional Hybrid Hydrogel Promotes Wound Healing. Adv. Funct. Mater. 28, 1801386. doi:10.1002/adfm.201801386

Chen, H., Cheng, R., Zhao, X., Zhang, Y., Tam, A., Yan, Y., et al. (2019). An Injectable Self-Healing Coordinative Hydrogel with Antibacterial and Angiogenic Properties for Diabetic Skin Wound Repair. NPG Asia Mater. 11, 1-12. doi:10.1038/s41427-018-0103-9

Chen, H., Jia, P., Kang, H., Zhang, H., Liu, Y., Yang, P., et al. (2016). Upregulating Hif-1 $\alpha$ by Hydrogel Nanofibrous Scaffolds for Rapidly Recruiting Angiogenesis Relative Cells in Diabetic Wound. Adv. Healthc. Mater. 5, 907-918. doi:10.1002/adhm.201501018

Chen, M., Tian, J., Liu, Y., Cao, H., Li, R., Wang, J., et al. (2019). Dynamic Covalent Constructed Self-Healing Hydrogel for Sequential Delivery of Antibacterial Agent and Growth Factor in Wound Healing. Chem. Eng. J. 373, 413-424. doi:10.1016/j.cej.2019.05.043

Chen, S., Shi, J., Zhang, M., Chen, Y., Wang, X., Zhang, L., et al. (2015). Mesenchymal Stem Cell-Laden Anti-inflammatory Hydrogel Enhances Diabetic Wound Healing. Sci. Rep. 5, 18104. doi:10.1038/srep18104

Cheng, H., Shi, Z., Yue, K., Huang, X., Xu, Y., Gao, C., et al. (2021). Sprayable Hydrogel Dressing Accelerates Wound Healing with Combined Reactive Oxygen Species-Scavenging and Antibacterial Abilities. Acta Biomater. 124, 219-232. doi:10.1016/j.actbio.2021.02.002

Cheng, L., Cai, Z., Ye, T., Yu, X., Chen, Z., Yan, Y., et al. (2020). Injectable Polypeptide-Protein Hydrogels for Promoting Infected Wound Healing. Adv. Funct. Mater. 30, 2001196. doi:10.1002/adfm.202001196

Cheng, N.-C., Lin, W.-J., Ling, T.-Y., and Young, T.-H. (2017). Sustained Release of Adipose-Derived Stem Cells by Thermosensitive Chitosan/gelatin Hydrogel for Therapeutic Angiogenesis. Acta Biomater. 51, 258-267. doi:10.1016/ j.actbio.2017.01.060

Choi, S.-K., Park, J.-K., Kim, J.-H., Lee, K.-M., Kim, E., Jeong, K.-S., et al. (2016). Integrin-binding Elastin-like Polypeptide as an In Situ Gelling Delivery Matrix Enhances the Therapeutic Efficacy of Adipose Stem Cells in Healing FullThickness Cutaneous Wounds. J. Controlled Release 237, 89-100. doi:10.1016/ j.jconrel.2016.07.006

Chwalek, K., Tsurkan, M. V., Freudenberg, U., and Werner, C. (2014). Glycosaminoglycan-based Hydrogels to Modulate Heterocellular Communication in In Vitro Angiogenesis Models. Sci. Rep. 4, 4414. doi:10.1038/srep04414

Cui, T., Li, X., He, S., Xu, D., Yin, L., Huang, X., et al. (2020). Instant Self-Assembly Peptide Hydrogel Encapsulation with Fibrous Alginate by Microfluidics for Infected Wound Healing. ACS Biomater. Sci. Eng. 6, 5001-5011. doi:10.1021/ acsbiomaterials.0c00581

da Silva, L. P., Cerqueira, M. T., Correlo, V. M., Reis, R. L., and Marques, A. P. (2016). "Engineered Hydrogel-Based Matrices for Skin Wound Healing," in Wound Healing Biomaterials. Editor Agren, M. S. (Braga, Portugal: Functional Biomaterials), 227-250. doi:10.1016/b978-1-78242-456-7.00011-8

da Silva, L. P., Santos, T. C., Rodrigues, D. B., Pirraco, R. P., Cerqueira, M. T., Reis, R. L., et al. (2017). Stem Cell-Containing Hyaluronic Acid-Based Spongy Hydrogels for Integrated Diabetic Wound Healing. J. Invest. Dermatol. 137, 1541-1551. doi:10.1016/j.jid.2017.02.976

Dai, J., Chen, H., and Chai, Y. (2019). Advanced Glycation End Products (AGEs) Induce Apoptosis of Fibroblasts by Activation of NLRP3 Inflammasome via Reactive Oxygen Species (ROS) Signaling Pathway. Med. Sci. Monit. 25, 7499-7508. doi:10.12659/MSM.915806

Dang, L. H., Huynh, N. T., Pham, N. O., Nguyen, C. T., Vu, M. T., Dinh, V. T., et al. (2019). Injectable Nanocurcumin-Dispersed Gelatin-Pluronic Nanocomposite Hydrogel Platform for Burn Wound Treatment. Bull. Mater. Sci. 42, 71. doi:10.1007/s12034-019-1745-0

Darling, N. J., Sideris, E., Hamada, N., Carmichael, S. T., and Segura, T. (2018). Injectable and Spatially Patterned Microporous Annealed Particle (MAP) Hydrogels for Tissue Repair Applications. Adv. Sci. 5, 1801046. doi:10.1002/ advs.201801046

Das, S., Singh, G., Majid, M., Sherman, M. B., Mukhopadhyay, S., Wright, C. S., et al. (2016). Syndesome Therapeutics for Enhancing Diabetic Wound Healing. Adv. Healthc. Mater. 5, 2248-2260. doi:10.1002/adhm.201600285 
Davis, G. E., and Senger, D. R. (2005). Endothelial Extracellular Matrix. Circ. Res. 97, 1093-1107. doi:10.1161/01.RES.0000191547.64391.e3

Demirci, S., Doğan, A., Aydın, S., Dülger, E. Ç., and Şahin, F. (2016). Boron Promotes Streptozotocin-Induced Diabetic Wound Healing: Roles in Cell Proliferation and Migration, Growth Factor Expression, and Inflammation. Mol. Cel Biochem 417, 119-133. doi:10.1007/s11010-016-2719-9

den Dekker, A., Davis, F. M., Kunkel, S. L., and Gallagher, K. A. (2019). Targeting Epigenetic Mechanisms in Diabetic Wound Healing. Translational Res. 204, 39-50. doi:10.1016/j.trsl.2018.10.001

Dong, Y., Cui, M., Qu, J., Wang, X., Kwon, S. H., Barrera, J., et al. (2020). Conformable Hyaluronic Acid Hydrogel Delivers Adipose-Derived Stem Cells and Promotes Regeneration of Burn Injury. Acta Biomater. 108, 56-66. doi:10.1016/j.actbio.2020.03.040

Dong, Y., Rodrigues, M., Kwon, S. H., Li, X., A, S., Brett, E. A., et al. (2018). Acceleration of Diabetic Wound Regeneration Using an In Situ-Formed StemCell-Based Skin Substitute. Adv. Healthc. Mater. 7, 1800432. doi:10.1002/ adhm.201800432

Dongen, J. A., Getova, V., Brouwer, L. A., Liguori, G. R., Sharma, P. K., Stevens, H. P., et al. (2019). Adipose Tissue-derived Extracellular Matrix Hydrogels as a Release Platform for Secreted Paracrine Factors. J. Tissue Eng. Regen. Med. 13, 973-985. doi:10.1002/term.2843

Du, Y., Li, L., Peng, H., Zheng, H., Cao, S., Lv, G., et al. (2020). A Spray-Filming Self-Healing Hydrogel Fabricated from Modified Sodium Alginate and Gelatin as a Bacterial Barrier. Macromol. Biosci. 20, 1900303. doi:10.1002/ mabi.201900303

Fife, C., and Carter, M. J. (2012). Wound Care Outcomes and Associated Cost Among Patients Treated in US Outpatient Wound Centers: Data from the US Wound Registry. Wounds 24, 10-17.

Freudenberg, U., Zieris, A., Chwalek, K., Tsurkan, M. V., Maitz, M. F., Atallah, P., et al. (2015). Heparin Desulfation Modulates VEGF Release and Angiogenesis in Diabetic Wounds. J. Control. Release 220, 79-88. doi:10.1016/ j.jconrel.2015.10.028

Frykberg, R. G., and Banks, J. (2015). Challenges in the Treatment of Chronic Wounds. Adv. Wound Care 4, 560-582. doi:10.1089/wound.2015.0635

Gao, M., Nguyen, T. T., Suckow, M. A., Wolter, W. R., Gooyit, M., Mobashery, S., et al. (2015). Acceleration of Diabetic Wound Healing Using a Novel ProteaseAnti-Protease Combination Therapy. Proc. Natl. Acad. Sci. USA 112, 15226-15231. doi:10.1073/pnas.1517847112

Gao, Y., Li, Z., Huang, J., Zhao, M., and Wu, J. (2020). In Situ formation of Injectable Hydrogels for Chronic Wound Healing. J. Mater. Chem. B 8, 8768-8780. doi:10.1039/d0tb01074j

Garg, R. K., Rennert, R. C., Duscher, D., Sorkin, M., Kosaraju, R., Auerbach, L. J., et al. (2014). Capillary Force Seeding of Hydrogels for Adipose-Derived Stem Cell Delivery in Wounds. Stem Cell Translational Med. 3, 1079-1089. doi:10.5966/sctm.2014-0007

Gau, E., Mate, D. M., Zou, Z., Oppermann, A., Töpel, A., Jakob, F., et al. (2017). Sortase-Mediated Surface Functionalization of StimuliResponsive Microgels. Biomacromolecules 18, 2789-2798. doi:10.1021/ acs.biomac. $7 \mathrm{~b} 00720$

Goh, M., Hwang, Y., and Tae, G. (2016). Epidermal Growth Factor Loaded Heparin-Based Hydrogel Sheet for Skin Wound Healing. Carbohydr. Polym. 147, 251-260. doi:10.1016/j.carbpol.2016.03.072

Gong, C., Wu, Q., Wang, Y., Zhang, D., Luo, F., Zhao, X., et al. (2013). A Biodegradable Hydrogel System Containing Curcumin Encapsulated in Micelles for Cutaneous Wound Healing. Biomaterials 34, 6377-6387. doi:10.1016/j.biomaterials.2013.05.005

Griffin, D. R., Archang, M. M., Kuan, C.-H., Weaver, W. M., Weinstein, J. S., Feng, A. C., et al. (2020). Activating an Adaptive Immune Response from a Hydrogel Scaffold Imparts Regenerative Wound Healing. Nat. Mater. 20, 560-569. doi:10.1038/s41563-020-00844-w

Griffin, D. R., Weaver, W. M., Scumpia, P. O., Di Carlo, D., and Segura, T. (2015). Accelerated Wound Healing by Injectable Microporous Gel Scaffolds Assembled from Annealed Building Blocks. Nat. Mater 14, 737-744. doi:10.1038/nmat4294

Grip, J., Engstad, R. E., Skjæveland, I., Škalko-Basnet, N., and Holsæter, A. M. (2017). Sprayable Carbopol Hydrogel with Soluble Beta-1,3/1,6-Glucan as an Active Ingredient for Wound Healing - Development and Iin-Vvivo Evaluation. Eur. J. Pharm. Sci. 107, 24-31. doi:10.1016/j.ejps.2017.06.029
Guo, B., and Ma, P. X. (2018). Conducting Polymers for Tissue Engineering. Biomacromolecules 19, 1764-1782. doi:10.1021/acs.biomac.8b00276

Guo, G., Li, X., Ye, X., Qi, J., Fan, R., Gao, X., et al. (2016). EGF and Curcumin Coencapsulated Nanoparticle/hydrogel System as Potent Skin Regeneration Agent. Int. J. Nanomedicine 11, 3993-4009. doi:10.2147/ijn.S104350

Hafezi, F., Scoutaris, N., Douroumis, D., and Boateng, J. (2019). 3D Printed Chitosan Dressing Crosslinked with Genipin for Potential Healing of Chronic Wounds. Int. J. Pharmaceutics 560, 406-415. doi:10.1016/ j.ijpharm.2019.02.020

Hajimiri, M., Shahverdi, S., Esfandiari, M. A., Larijani, B., Atyabi, F., Rajabiani, A., et al. (2016). Preparation of Hydrogel Embedded Polymer-Growth Factor Conjugated Nanoparticles as a Diabetic Wound Dressing. Drug Dev. Ind. Pharm. 42, 707-719. doi:10.3109/03639045.2015.1075030

Ham, H. O., Qu, Z., Haller, C. A., Dorr, B. M., Dai, E., Kim, W., et al. (2016). In Situ regeneration of Bioactive Coatings Enabled by an Evolved Staphylococcus aureus Sortase A. Nat. Commun. 7, 1-8. doi:10.1038/ncomms11140

Hanjaya-Putra, D., Bose, V., Shen, Y.-I., Yee, J., Khetan, S., Fox-Talbot, K., et al. (2011). Controlled Activation of Morphogenesis to Generate a Functional Human Microvasculature in a Synthetic Matrix. Blood 118, 804-815. doi:10.1182/blood-2010-12-327338

Hanjaya-Putra, D., Shen, Y.-I., Wilson, A., Fox-Talbot, K., Khetan, S., Burdick, J. A., et al. (2013). Integration and Regression of Implanted Engineered Human Vascular Networks during Deep Wound Healing. Stem Cells Transl. Med. 2, 297-306. doi:10.5966/sctm.2012-0111

Hanjaya-Putra, D., Wong, K. T., Hirotsu, K., Khetan, S., Burdick, J. A., and Gerecht, S. (2012). Spatial Control of Cell-Mediated Degradation to Regulate Vasculogenesis and Angiogenesis in Hyaluronan Hydrogels. Biomaterials 33, 6123-6131. doi:10.1016/j.biomaterials.2012.05.027

Henderson, P. W., Singh, S. P., Krijgh, D. D., Yamamoto, M., Rafii, D. C., Sung, J. J., et al. (2011). Stromal-derived Factor-1 Delivered via Hydrogel Drug-Delivery Vehicle Accelerates Wound Healing In Vivo. Wound Repair Regen. 19, 420-425. doi:10.1111/j.1524-475X.2011.00687.x

Hill, R. P., Gledhill, K., Gardner, A., Higgins, C. A., Crawford, H., Lawrence, C., et al. (2012). Generation and Characterization of Multipotent Stem Cells from Established Dermal Cultures. PLoS One 7, e50742. doi:10.1371/ journal.pone.0050742

Hoque, J., Prakash, R. G., Paramanandham, K., Shome, B. R., and Haldar, J. (2017). Biocompatible Injectable Hydrogel with Potent Wound Healing and Antibacterial Properties. Mol. Pharmaceutics 14, 1218-1230. doi:10.1021/ acs.molpharmaceut.6b01104

Houdek, M. T., Wyles, C. C., Stalboerger, P. G., Terzic, A., Behfar, A., and Moran, S. L. (2016). Collagen and Fractionated Platelet-Rich Plasma Scaffold for Dermal Regeneration. Plast. Reconstr. Surg. 137, 1498-1506. doi:10.1097/ prs.0000000000002094

Hsieh, C.-M., Wang, W., Chen, Y.-H., Wei, P.-S., Liu, Y.-H., Sheu, M.-T., et al. (2020). A Novel Composite Hydrogel Composed of Formic AcidDecellularized Pepsin-Soluble Extracellular Matrix Hydrogel and Sacchachitin Hydrogel as Wound Dressing to Synergistically Accelerate Diabetic Wound Healing. Pharmaceutics 12, 538. doi:10.3390/ pharmaceutics 12060538

Hsu, L.-C., Peng, B.-Y., Chen, M.-S., Thalib, B., Ruslin, M., Tung, T. D. X., et al. (2019). The Potential of the Stem Cells Composite Hydrogel Wound Dressings for Promoting Wound Healing and Skin Regeneration: In Vitro and In Vivo Evaluation. J. Biomed. Mater. Res. 107, 278-285. doi:10.1002/jbm.b.34118

Huang, C., Orbay, H., Tobita, M., Miyamoto, M., Tabata, Y., Hyakusoku, H., et al. (2016). Proapoptotic Effect of Control-Released Basic Fibroblast Growth Factor on Skin Wound Healing in a Diabetic Mouse Model. Wound Rep. Reg. 24, 65-74. doi:10.1111/wrr.12375

Huang, E., Heyboer III, M., and Savaser, D. J. (2019). Hyperbaric Oxygen Therapy for the Management of Chronic Wounds: Patient Selection and Perspectives. Cwcmr 6, 27-37. doi:10.2147/CWCMR.S175721

Huang, J., Ren, J., Chen, G., Li, Z., Liu, Y., Wang, G., et al. (2018). Tunable Sequential Drug Delivery System Based on Chitosan/hyaluronic Acid Hydrogels and PLGA Microspheres for Management of Non-healing Infected Wounds. Mater. Sci. Eng. C 89, 213-222. doi:10.1016/ j.msec.2018.04.009

Huang, S., Zhang, Y., Tang, L., Deng, Z., Lu, W., Feng, F., et al. (2009). Functional Bilayered Skin Substitute Constructed by Tissue-Engineered Extracellular 
Matrix and Microsphere-Incorporated Gelatin Hydrogel for Wound Repair. Tissue Eng. A 15, 2617-2624. doi:10.1089/ten.tea.2008.0505

Huang, W., Wang, Y., Huang, Z., Wang, X., Chen, L., Zhang, Y., et al. (2018). OnDemand Dissolvable Self-Healing Hydrogel Based on Carboxymethyl Chitosan and Cellulose Nanocrystal for Deep Partial Thickness Burn Wound Healing. ACS Appl. Mater. Inter. 10, 41076-41088. doi:10.1021/acsami.8b14526

Ibrahim, S., and Ramamurthi, A. (2008). Hyaluronic Acid Cues for Functional Endothelialization of Vascular Constructs. J. Tissue Eng. Regen. Med. 2, 22-32. doi:10.1002/term.61

Jessen, K. R., Mirsky, R., and Lloyd, A. C. (2015). Schwann Cells: Development and Role in Nerve Repair. Cold Spring Harb Perspect. Biol. 7, a020487. doi:10.1101/ cshperspect.a020487

Johnson, K.-a., Muzzin, N., Toufanian, S., Slick, R. A., Lawlor, M. W., Seifried, B., et al. (2020). Drug-impregnated, Pressurized Gas Expanded Liquid-Processed Alginate Hydrogel Scaffolds for Accelerated Burn Wound Healing. Acta Biomater. 112, 101-111. doi:10.1016/j.actbio.2020.06.006

Kaisang, L., Siyu, W., Lijun, F., Daoyan, P., Xian, C. J., and Jie, S. (2017). Adiposederived Stem Cells Seeded in Pluronic F-127 Hydrogel Promotes Diabetic Wound Healing. J. Surg. Res. 217, 63-74. doi:10.1016/j.jss.2017.04.032

Kant, V., Kumar, D., Kumar, D., Prasad, R., Gopal, A., Pathak, N. N., et al. (2015). Topical Application of Substance $\mathrm{P}$ Promotes Wound Healing in Streptozotocin-Induced Diabetic Rats. Cytokine 73, 144-155. doi:10.1016/ j.cyto.2014.12.015

Karavasili, C., Tsongas, K., Andreadis, I. I., Andriotis, E. G., Papachristou, E. T., Papi, R. M., et al. (2020). Physico-mechanical and Finite Element Analysis Evaluation of 3D Printable Alginate-Methylcellulose Inks for Wound Healing Applications. Carbohydr. Polym. 247, 116666. doi:10.1016/ j.carbpol.2020.116666

Kathawala, M. H., Ng, W. L., Liu, D., Naing, M. W., Yeong, W. Y., Spiller, K. L., et al. (2019). Healing of Chronic Wounds: An Update of Recent Developments and Future Possibilities. Tissue Eng. B: Rev. 25, 429-444. doi:10.1089/ ten.teb.2019.0019

Kim, E. J., Choi, J. S., Kim, J. S., Choi, Y. C., and Cho, Y. W. (2016). Injectable and Thermosensitive Soluble Extracellular Matrix and Methylcellulose Hydrogels for Stem Cell Delivery in Skin Wounds. Biomacromolecules 17, 4-11. doi:10.1021/acs.biomac.5b01566

Kim, H. S., Sun, X., Lee, J.-H., Kim, H.-W., Fu, X., and Leong, K. W. (2019). Advanced Drug Delivery Systems and Artificial Skin Grafts for Skin Wound Healing. Adv. Drug Deliv. Rev. 146, 209-239. doi:10.1016/ j.addr.2018.12.014

Kim, M. H., Park, H., Nam, H. C., Park, S. R., Jung, J.-Y., and Park, W. H. (2018). Injectable Methylcellulose Hydrogel Containing Silver Oxide Nanoparticles for Burn Wound Healing. Carbohydr. Polym. 181, 579-586. doi:10.1016/ j.carbpol.2017.11.109

Kim, Y.-H., and Tabata, Y. (2017). Enhancement of Wound Closure by Modifying Dual Release Patterns of Stromal-Derived Cell Factor-1 and a Macrophage Recruitment Agent from Gelatin Hydrogels. J. Tissue Eng. Regen. Med. 11, 2999-3013. doi:10.1002/term.2202

Kim, Y.-H., and Tabata, Y. (2016). Recruitment of Mesenchymal Stem Cells and Macrophages by Dual Release of Stromal Cell-Derived Factor-1 and a Macrophage Recruitment Agent Enhances Wound Closure. J. Biomed. Mater. Res. 104, 942-956. doi:10.1002/jbm.a.35635

Klar, A. S., Güven, S., Zimoch, J., Zapiórkowska, N. A., Biedermann, T., BöttcherHaberzeth, S., et al. (2016). Characterization of Vasculogenic Potential of Human Adipose-Derived Endothelial Cells in a Three-Dimensional Vascularized Skin Substitute. Pediatr. Surg. Int. 32, 17-27. doi:10.1007/ s00383-015-3808-7

Kong, L., Wu, Z., Zhao, H., Cui, H., Shen, J., Chang, J., et al. (2018). Bioactive Injectable Hydrogels Containing Desferrioxamine and Bioglass for Diabetic Wound Healing. ACS Appl. Mater. Inter. 10, 30103-30114. doi:10.1021/ acsami.8b09191

Konieczynska, M. D., Villa-Camacho, J. C., Ghobril, C., Perez-Viloria, M., Tevis, K. M., Blessing, W. A., et al. (2016). On-Demand Dissolution of a Dendritic Hydrogel-Based Dressing for Second-Degree Burn Wounds through ThiolThioester Exchange Reaction. Angew. Chem. Int. Ed. 55, 9984-9987. doi:10.1002/anie.201604827

Koria, P., Yagi, H., Kitagawa, Y., Megeed, Z., Nahmias, Y., Sheridan, R., et al. (2011). Self-assembling Elastin-like Peptides Growth Factor Chimeric
Nanoparticles for the Treatment of Chronic Wounds. Proc. Natl. Acad. Sci. 108, 1034-1039. doi:10.1073/pnas.1009881108

Kosaraju, R., Rennert, R. C., Maan, Z. N., Duscher, D., Barrera, J., Whittam, A. J., et al. (2016). Adipose-Derived Stem Cell-Seeded Hydrogels Increase Endogenous Progenitor Cell Recruitment and Neovascularization in Wounds. Tissue Eng. Part A 22, 295-305. doi:10.1089/ten.tea.2015.0277

Ku, S. H., Ryu, J., Hong, S. K., Lee, H., and Park, C. B. (2010). General Functionalization Route for Cell Adhesion on Non-wetting Surfaces. Biomaterials 31, 2535-2541. doi:10.1016/j.biomaterials.2009.12.020

Kumar, A., and Jaiswal, M. (2016). Design and In Vitro Investigation of Nanocomposite Hydrogel Based In Situ spray Dressing for Chronic Wounds and Synthesis of Silver Nanoparticles Using green Chemistry. J. Appl. Polym. Sci. 133, n/a. doi:10.1002/app.43260

Kumar, V. A., Taylor, N. L., Shi, S., Wang, B. K., Jalan, A. A., Kang, M. K., et al. (2015). Highly Angiogenic Peptide Nanofibers. ACS Nano 9, 860-868. doi:10.1021/nn506544b

Kusuma, S., Shen, Y.-I., Hanjaya-Putra, D., Mali, P., Cheng, L., and Gerecht, S. (2013). Self-organized Vascular Networks from Human Pluripotent Stem Cells in a Synthetic Matrix. Proc. Natl. Acad. Sci. 110, 12601-12606. doi:10.1073/ pnas. 1306562110

Lao, G., Yan, L., Yang, C., Zhang, L., Zhang, S., and Zhou, Y. (2012). Controlled Release of Epidermal Growth Factor from Hydrogels Accelerates Wound Healing in Diabetic Rats. J. Am. Podiatric Med. Assoc. 102, 89-98. doi:10.7547/1020089

Laverdet, B., Danigo, A., Girard, D., Magy, L., Demiot, C., and Desmoulière, A. (2015). Skin Innervation: Important Roles during normal and Pathological Cutaneous Repair. Histol. Histopathol 30, 875-892. doi:10.14670/hh-11-610

Leavitt, T., Hu, M. S., Marshall, C. D., Barnes, L. A., Lorenz, H. P., and Longaker, M. T. (2016). Scarless Wound Healing: Finding the Right Cells and Signals. Cell Tissue Res 365, 483-493. doi:10.1007/s00441-016-2424-8

Lee, J., Hlaing, S. P., Cao, J., Hasan, N., Ahn, H.-J., Song, K.-W., et al. (2019). In Situ Hydrogel-Forming/Nitric Oxide-Releasing Wound Dressing for Enhanced Antibacterial Activity and Healing in Mice with Infected Wounds. Pharmaceutics 11, 496. doi:10.3390/pharmaceutics11100496

Lee, Y.-H., Chang, J.-J., Yang, M.-C., Chien, C.-T., and Lai, W.-F. (2012). Acceleration of Wound Healing in Diabetic Rats by Layered Hydrogel Dressing. Carbohydr. Polym. 88, 809-819. doi:10.1016/j.carbpol.2011.12.045

Lee, Y., Bae, J. W., Lee, J. W., Suh, W., and Park, K. D. (2014). Enzyme-catalyzed In Situ Forming Gelatin Hydrogels as Bioactive Wound Dressings: Effects of Fibroblast Delivery on Wound Healing Efficacy. J. Mater. Chem. B 2, 7712-7718. doi:10.1039/c4tb01111b

Lei, Z., Singh, G., Min, Z., Shixuan, C., Xu, K., Pengcheng, X., et al. (2018). Bone Marrow-Derived Mesenchymal Stem Cells Laden Novel Thermo-Sensitive Hydrogel for the Management of Severe Skin Wound Healing. Mater. Sci. Eng. C 90, 159-167. doi:10.1016/j.msec.2018.04.045

Li, J., Yu, F., Chen, G., Liu, J., Li, X.-L., Cheng, B., et al. (2020). Moist-Retaining, Self-Recoverable, Bioadhesive, and Transparent In Situ Forming Hydrogels to Accelerate Wound Healing. ACS Appl. Mater. Inter. 12, 2023-2038. doi:10.1021/acsami.9b17180

Li, W., Wang, S., Zhong, D., Du, Z., and Zhou, M. (2021). A Bioactive Living Hydrogel: Photosynthetic Bacteria Mediated Hypoxia Elimination and Bacteria-Killing to Promote Infected Wound Healing. Adv. Therap. 4, 2000107. doi:10.1002/adtp.202000107

Li, X., Fan, R., Tong, A., Yang, M., Deng, J., Zhou, L., et al. (2015). In Situ gelforming AP-57 Peptide Delivery System for Cutaneous Wound Healing. Int. J. Pharmaceutics 495, 560-571. doi:10.1016/j.ijpharm.2015.09.005

Li, Y., Zhu, C., Fan, D., Fu, R., Ma, P., Duan, Z., et al. (2019). A Bi-Layer PVA/ CMC/PEG Hydrogel with Gradually Changing Pore Sizes for Wound Dressing. Macromol. Biosci. 19, 1800424. doi:10.1002/mabi.201800424

Li, Z., Yuan, B., Dong, X., Duan, L., Tian, H., He, C., et al. (2015). Injectable Polysaccharide Hybrid Hydrogels as Scaffolds for Burn Wound Healing. RSC Adv. 5, 94248-94256. doi:10.1039/c5ra16912g

Li, Z., Zhou, F., Li, Z., Lin, S., Chen, L., Liu, L., et al. (2018). Hydrogel Cross-Linked with Dynamic Covalent Bonding and Micellization for Promoting Burn Wound Healing. ACS Appl. Mater. Inter. 10, 25194-25202. doi:10.1021/ acsami.8b08165

Liang, Y., Chen, B., Li, M., He, J., Yin, Z., and Guo, B. (2020). Injectable Antimicrobial Conductive Hydrogels for Wound Disinfection and Infectious 
Wound Healing. Biomacromolecules 21, 1841-1852. doi:10.1021/ acs.biomac.9b01732

Liang, Y., Zhao, X., Hu, T., Chen, B., Yin, Z., Ma, P. X., et al. (2019). Adhesive Hemostatic Conducting Injectable Composite Hydrogels with Sustained Drug Release and Photothermal Antibacterial Activity to Promote Full-Thickness Skin Regeneration during Wound Healing. Small 15, 1900046. doi:10.1002/ smll.201900046

Liang, Y., Zhao, X., Hu, T., Han, Y., and Guo, B. (2019). Mussel-inspired, Antibacterial, Conductive, Antioxidant, Injectable Composite Hydrogel Wound Dressing to Promote the Regeneration of Infected Skin. J. Colloid Interf. Sci. 556, 514-528. doi:10.1016/j.jcis.2019.08.083

Lin, W., Qi, X., Guo, W., Liang, D., Chen, H., Lin, B., et al. (2020). A Barrier against Reactive Oxygen Species: Chitosan/acellular Dermal Matrix Scaffold Enhances Stem Cell Retention and Improves Cutaneous Wound Healing. Stem Cell Res. Ther. 11, 383. doi:10.1186/s13287-020-01901-6

Liu, G., Bao, Z., and Wu, J. (2020). Injectable baicalin/F127 Hydrogel with Antioxidant Activity for Enhanced Wound Healing. Chin. Chem. Lett. 31, 1817-1821. doi:10.1016/j.cclet.2020.03.005

Liu, H., Zhao, Y., Zou, Y., Huang, W., Zhu, L., Liu, F., et al. (2019). Heparinpoloxamer Hydrogel-encapsulated rhFGF21 Enhances Wound Healing in Diabetic Mice. FASEB j. 33, 9858-9870. doi:10.1096/fj.201802600RR

Liu, J., Chen, Z., Wang, J., Li, R., Li, T., Chang, M., et al. (2018). Encapsulation of Curcumin Nanoparticles with MMP9-Responsive and Thermos-Sensitive Hydrogel Improves Diabetic Wound Healing. ACS Appl. Mater. Inter. 10, 16315-16326. doi:10.1021/acsami.8b03868

Liu, S., Zhang, Q., Yu, J., Shao, N., Lu, H., Guo, J., et al. (2020). Absorbable Thioether Grafted Hyaluronic Acid Nanofibrous Hydrogel for Synergistic Modulation of Inflammation Microenvironment to Accelerate Chronic Diabetic Wound Healing. Adv. Healthc. Mater. 9, 2000198. doi:10.1002/ adhm.202000198

Liu, Y., Cai, S., Shu, X. Z., Shelby, J., and Prestwich, G. D. (2007). Release of Basic Fibroblast Growth Factor from a Crosslinked Glycosaminoglycan Hydrogel Promotes Wound Healing. Wound Repair Regen. 15, 245-251. doi:10.1111/ j.1524-475X.2007.00211.x

Lohmann, N., Schirmer, L., Atallah, P., Wandel, E., Ferrer, R. A., Werner, C., et al. (2017). Glycosaminoglycan-based Hydrogels Capture Inflammatory Chemokines and rescue Defective Wound Healing in Mice. Sci. Transl. Med. 9, eaai9044. doi:10.1126/scitranslmed.aai9044

Lokhande, G., Carrow, J. K., Thakur, T., Xavier, J. R., Parani, M., Bayless, K. J., et al. (2018). Nanoengineered Injectable Hydrogels for Wound Healing Application. Acta Biomater. 70, 35-47. doi:10.1016/j.actbio.2018.01.045

Long, J., Etxeberria, A. E., Nand, A. V., Bunt, C. R., Ray, S., and Seyfoddin, A. (2019). A 3D Printed Chitosan-Pectin Hydrogel Wound Dressing for Lidocaine Hydrochloride Delivery. Mater. Sci. Eng. C 104, 109873. doi:10.1016/ j.msec.2019.109873

Loots, M. A. M., Lamme, E. N., Zeegelaar, J., Mekkes, J. R., Bos, J. D., and Middelkoop, E. (1998). Differences in Cellular Infiltrate and Extracellular Matrix of Chronic Diabetic and Venous Ulcers versus Acute Wounds. J. Invest. Dermatol. 111, 850-857. doi:10.1046/j.1523-1747.1998.00381.x

Luckanagul, J. A., Pitakchatwong, C., Ratnatilaka Na Bhuket, P., Muangnoi, C., Rojsitthisak, P., Chirachanchai, S., et al. (2018). Chitosan-based Polymer Hybrids for Thermo-Responsive Nanogel Delivery of Curcumin. Carbohydr. Polym. 181, 1119-1127. doi:10.1016/j.carbpol.2017.11.027

Ma, Z., Song, W., He, Y., and Li, H. (2020). Multilayer Injectable Hydrogel System Sequentially Delivers Bioactive Substances for Each Wound Healing Stage. ACS Appl. Mater. Inter. 12, 29787-29806. doi:10.1021/acsami.0c06360

Mai, B., Jia, M., Liu, S., Sheng, Z., Li, M., Gao, Y., et al. (2020). Smart HydrogelBased DVDMS/bFGF Nanohybrids for Antibacterial Phototherapy with Multiple Damaging Sites and Accelerated Wound Healing. ACS Appl. Mater. Inter. 12, 10156-10169. doi:10.1021/acsami.0c00298

Maris, P. (1995). Modes of Action of Disinfectants. Rev. Sci. Tech. OIE 14, 47-55. doi:10.20506/rst.14.1.829

Maruyama, K., Asai, J., Ii, M., Thorne, T., Losordo, D. W., and D’Amore, P. A. (2007). Decreased Macrophage Number and Activation lead to Reduced Lymphatic Vessel Formation and Contribute to Impaired Diabetic Wound Healing. Am. J. Pathol. 170, 1178-1191. doi:10.2353/ajpath.2007.060018

Masters, K. S. B., Leibovich, S. J., Belem, P., West, J. L., and Poole-Warren, L. A. (2002). Effects of Nitric Oxide Releasing Poly(vinyl Alcohol) Hydrogel
Dressings on Dermal Wound Healing in Diabetic Mice. Wound Repair Regen. 10, 286-294. doi:10.1046/j.1524-475X.2002.10503.x

Milan, P. B., Lotfibakhshaiesh, N., Joghataie, M. T., Ai, J., Pazouki, A., Kaplan, D. L., et al. (2016). Accelerated Wound Healing in a Diabetic Rat Model Using Decellularized Dermal Matrix and Human Umbilical Cord Perivascular Cells. Acta Biomater. 45, 234-246. doi:10.1016/j.actbio.2016.08.053

Mohamad, N., Loh, E. Y. X., Fauzi, M. B., Ng, M. H., and Mohd Amin, M. C. I. (2019). In Vivo evaluation of Bacterial Cellulose/acrylic Acid Wound Dressing Hydrogel Containing Keratinocytes and Fibroblasts for Burn Wounds. Drug Deliv. Transl. Res. 9, 444-452. doi:10.1007/s13346-0170475-3

Mohandas, A., Anisha, B. S., Chennazhi, K. P., and Jayakumar, R. (2015). Chitosanhyaluronic Acid/VEGF Loaded Fibrin Nanoparticles Composite Sponges for Enhancing Angiogenesis in Wounds. Colloids Surf. B: Biointerfaces 127, 105-113. doi:10.1016/j.colsurfb.2015.01.024

Mohandas, A., Nimal, T. R., Das, V., Shankarappa, S. A., Biswas, R., and Jayakumar, R. (2015). Drug Loaded Bi-layered Sponge for Wound Management in Hyperfibrinolytic Conditions. J. Mater. Chem. B 3, 5795-5805. doi:10.1039/c5tb00568j

Mohd Zohdi, R., Abu Bakar Zakaria, Z., Yusof, N., Mohamed Mustapha, N., and Abdullah, M. N. H. (2012). Gelam (Melaleucaspp.) Honey-Based Hydrogel as Burn Wound Dressing. Evidence-Based Complement. Altern. Med. 2012, 1-7. doi:10.1155/2012/843025

Monteforte, A. J., Lam, B., Das, S., Mukhopadhyay, S., Wright, C. S., Martin, P. E., et al. (2016). Glypican-1 Nanoliposomes for Potentiating Growth Factor Activity in Therapeutic Angiogenesis. Biomaterials 94, 45-56. doi:10.1016/ j.biomaterials.2016.03.048

Moon, J. J., Saik, J. E., Poché, R. A., Leslie-Barbick, J. E., Lee, S.-H., Smith, A. A., et al. (2010). Biomimetic Hydrogels with Pro-angiogenic Properties. Biomaterials 31, 3840-3847. doi:10.1016/j.biomaterials.2010.01.104

Moore, K., Ruge, F., and Harding, K. G. (1997). T Lymphocytes and the Lack of Activated Macrophages in Wound Margin Biopsies from Chronic Leg Ulcers. Br. J. Dermatol. 137, 188-194. doi:10.1046/j.1365-2133.1997.18041895.x

Morris, A. H., Lee, H., Xing, H., Stamer, D. K., Tan, M., and Kyriakides, T. R. (2018). Tunable Hydrogels Derived from Genetically Engineered Extracellular Matrix Accelerate Diabetic Wound Healing. ACS Appl. Mater. Inter. 10, 41892-41901. doi:10.1021/acsami.8b08920

Moura, L. I. F., Dias, A. M. A., Suesca, E., Casadiegos, S., Leal, E. C., Fontanilla, M. R., et al. (2014). Neurotensin-loaded Collagen Dressings Reduce Inflammation and Improve Wound Healing in Diabetic Mice. Biochim. Biophys. Acta (Bba) Mol. Basis Dis. 1842, 32-43. doi:10.1016/j.bbadis.2013.10.009

Muir, V. G., Qazi, T. H., Shan, J., Groll, J., and Burdick, J. A. (2021). Influence of Microgel Fabrication Technique on Granular Hydrogel Properties. ACS Biomater. Sci. Eng. [Epub ahead of print]. doi:10.1021/acsbiomaterials.0c01612

Muthuswamy, S., Viswanathan, A., Yegappan, R., Selvaprithiviraj, V., Vasudevan, A. K., Biswas, R., et al. (2019). Antistaphylococcal and Neutrophil Chemotactic Injectable $\kappa$-Carrageenan Hydrogel for Infectious Wound Healing. ACS Appl. Bio Mater. 2, 378-387. doi:10.1021/acsabm.8b00625

Naghibi, M., Smith, R. P., Baltch, A. L., Gates, S. A., Wu, D. H., Hammer, M. C., et al. (1987). The Effect of Diabetes Mellitus on Chemotactic and Bactericidal Activity of Human Polymorphonuclear Leukocytes. Diabetes Res. Clin. Pract. 4, 27-35. doi:10.1016/S0168-8227(87)80030-X

Natesan, S., Zamora, D. O., Wrice, N. L., Baer, D. G., and Christy, R. J. (2013). Bilayer Hydrogel with Autologous Stem Cells Derived from Debrided Human Burn Skin for Improved Skin Regeneration. J. Burn Care Res. 34, 18-30. doi:10.1097/BCR.0b013e3182642c0e

Ng, W. L., Yeong, W. Y., and Naing, M. W. (2016). Polyelectrolyte GelatinChitosan Hydrogel Optimized for 3D Bioprinting in Skin Tissue Engineering. Int. J. Bioprinting 2, 53-62. doi:10.18063/IJB.2016.01.009

Nguyen, T. T., Ding, D., Wolter, W. R., Pérez, R. L., Champion, M. M., Mahasenan, K. V., et al. (2018). Validation of Matrix Metalloproteinase-9 (MMP-9) as a Novel Target for Treatment of Diabetic Foot Ulcers in Humans and Discovery of a Potent and Selective Small-Molecule MMP-9 Inhibitor that Accelerates Healing. J. Med. Chem. 61, 8825-8837. doi:10.1021/acs.jmedchem.8b01005

Nie, C., Zhang, G., Yang, D., Liu, T., Liu, D., Xu, J., et al. (2015). Targeted Delivery of Adipose-Derived Stem Cells via Acellular Dermal Matrix Enhances Wound Repair in Diabetic Rats. J. Tissue Eng. Regen. Med. 9, 224-235. doi:10.1002/ term. 1622 
Notodihardjo, P. V., Morimoto, N., Kakudo, N., Matsui, M., Sakamoto, M., Liem, P. H., et al. (2015). Gelatin Hydrogel Impregnated with Platelet-Rich Plasma Releasate Promotes Angiogenesis and Wound Healing in Murine Model. J. Artif. Organs 18, 64-71. doi:10.1007/s10047-014-0795-8

Orive, G., de Castro, M., Kong, H.-J., Hernández, R. M., Ponce, S., Mooney, D. J., et al. (2009). Bioactive Cell-Hydrogel Microcapsules for Cell-Based Drug Delivery. J. Controlled Release 135, 203-210. doi:10.1016/j.jconrel.2009.01.005

Oryan, A., Alemzadeh, E., Mohammadi, A. A., and Moshiri, A. (2019). Healing Potential of Injectable Aloe Vera Hydrogel Loaded by Adipose-Derived Stem Cell in Skin Tissue-Engineering in a Rat Burn Wound Model. Cel Tissue Res 377, 215-227. doi:10.1007/s00441-019-03015-9

Pan, Z., Bui, L., Yadav, V., Fan, F., Chang, H.-C., and Hanjaya-Putra, D. (2021). Conformal Single Cell Hydrogel Coating with Electrically Induced Tip Streaming of an AC Cone. Biomater. Sci. 9, 3284-3292. doi:10.1039/ dobm02100h

Park, Y. G., Lee, I. H., Park, E. S., and Kim, J. Y. (2017). Hydrogel and Platelet-Rich Plasma Combined Treatment to Accelerate Wound Healing in a Nude Mouse Model. Arch. Plast. Surg. 44, 194-201. doi:10.5999/aps.2017.44.3.194

Peng, Z., Nguyen, T. T., Song, W., Anderson, B., Wolter, W. R., Schroeder, V. A., et al. (2021). Selective MMP-9 Inhibitor (R)-ND-336 Alone or in Combination with Linezolid Accelerates Wound Healing in Infected Diabetic Mice. ACS Pharmacol. Transl. Sci. 4, 107-117. doi:10.1021/acsptsci.0c00104

$\mathrm{Pu}, \mathrm{W} .$, Ren, J., Chen, Y., Shu, J., Cui, L., Han, Y., et al. (2020). Injectable Human Decellularized Adipose Tissue Hydrogel Containing Stem Cells Enhances Wound Healing in Mouse. Colloids Surf. A: Physicochemical Eng. Aspects 604, 125268. doi:10.1016/j.colsurfa.2020.125268

Qiu, H., Pu, F., Liu, Z., Liu, X., Dong, K., Liu, C., et al. (2020). Hydrogel-based Artificial Enzyme for Combating Bacteria and Accelerating Wound Healing. Nano Res. 13, 496-502. doi:10.1007/s12274-020-2636-9

Qiu, M., Chen, D., Shen, C., Shen, J., Zhao, H., and He, Y. (2016). Platelet-Rich Plasma-Loaded Poly(d,l-Lactide)-Poly(ethylene Glycol)-Poly(d,l-Lactide) Hydrogel Dressing Promotes Full-Thickness Skin Wound Healing in a Rodent Model. Ijms 17, 1001. doi:10.3390/ijms17071001

Qu, J., Zhao, X., Liang, Y., Zhang, T., Ma, P. X., and Guo, B. (2018). Antibacterial Adhesive Injectable Hydrogels with Rapid Self-Healing, Extensibility and Compressibility as Wound Dressing for Joints Skin Wound Healing. Biomaterials 183, 185-199. doi:10.1016/j.biomaterials.2018.08.044

Rabbany, S. Y., Pastore, J., Yamamoto, M., Miller, T., Rafii, S., Aras, R., et al. (2010). Continuous Delivery of Stromal Cell-Derived Factor-1 from Alginate Scaffolds Accelerates Wound Healing. Cel Transpl. 19, 399-408. doi:10.3727/ 096368909x 481782

Reyes-Ortega, F., Cifuentes, A., Rodríguez, G., Aguilar, M. R., González-Gómez, Á., Solis, R., et al. (2015). Bioactive Bilayered Dressing for Compromised Epidermal Tissue Regeneration with Sequential Activity of Complementary Agents. Acta Biomater. 23, 103-115. doi:10.1016/j.actbio.2015.05.012

Rice, J. J., Martino, M. M., de Laporte, L., Tortelli, F., Briquez, P. S., and Hubbell, J. A. (2013). Engineering the Regenerative Microenvironment with Biomaterials. Adv. Healthc. Mater. 2, 57-71. doi:10.1002/adhm.201200197

Romić, M. D., Klarić, M. ̌̌., Lovrić, J., Pepić, I., Cetina-Čižmek, B., Filipović-Grčić, J., et al. (2016). Melatonin-loaded chitosan/Pluronic F127 Microspheres as In Situ Forming Hydrogel: An Innovative Antimicrobial Wound Dressing. Eur. J. Pharmaceutics Biopharmaceutics 107, 67-79. doi:10.1016/j.ejpb.2016.06.013

Rustad, K. C., Wong, V. W., Sorkin, M., Glotzbach, J. P., Major, M. R., Rajadas, J., et al. (2012). Enhancement of Mesenchymal Stem Cell Angiogenic Capacity and Stemness by a Biomimetic Hydrogel Scaffold. Biomaterials 33, 80-90. doi:10.1016/j.biomaterials.2011.09.041

Schanuel, F. S., Raggio Santos, K. S., Monte-Alto-Costa, A., and de Oliveira, M. G. (2015). Combined Nitric Oxide-Releasing Poly(vinyl Alcohol) film/F127 Hydrogel for Accelerating Wound Healing. Colloids Surf. B: Biointerfaces 130, 182-191. doi:10.1016/j.colsurfb.2015.04.007

Seliktar, D. (2012). Designing Cell-Compatible Hydrogels for Biomedical Applications. Science 336, 1124-1128. doi:10.1126/science.1214804

Shamloo, A., Sarmadi, M., Aghababaie, Z., and Vossoughi, M. (2018). Accelerated Full-Thickness Wound Healing via Sustained bFGF Delivery Based on a PVA/ chitosan/gelatin Hydrogel Incorporating PCL Microspheres. Int. J. Pharmaceutics 537, 278-289. doi:10.1016/j.ijpharm.2017.12.045
Shen, Y.-I., Cho, H., Papa, A. E., Burke, J. A., Chan, X. Y., Duh, E. J., et al. (2016). Engineered Human Vascularized Constructs Accelerate Diabetic Wound Healing. Biomaterials 102, 107-119. doi:10.1016/j.biomaterials.2016.06.009

Shi, Y., Truong, V. X., Kulkarni, K., Qu, Y., Simon, G. P., Boyd, R. L., et al. (2015). Light-triggered Release of Ciprofloxacin from an In Situ Forming Click Hydrogel for Antibacterial Wound Dressings. J. Mater. Chem. B 3, 8771-8774. doi:10.1039/c5tb01820j

Shou, K., Huang, Y., Qi, B., Hu, X., Ma, Z., Lu, A., et al. (2018). Induction of Mesenchymal Stem Cell Differentiation in the Absence of Soluble Inducer for Cutaneous Wound Regeneration by a Chitin Nanofiber-Based Hydrogel. J. Tissue Eng. Regen. Med. 12, E867-E880. doi:10.1002/term.2400

Shukla, R., Kashaw, S. K., Jain, A. P., and Lodhi, S. (2016). Fabrication of Apigenin Loaded Gellan Gum-Chitosan Hydrogels (GGCH-HGs) for Effective Diabetic Wound Healing. Int. J. Biol. Macromolecules 91, 1110-1119. doi:10.1016/ j.ijbiomac.2016.06.075

Skardal, A., Murphy, S. V., Crowell, K., Mack, D., Atala, A., and Soker, S. (2017). A Tunable Hydrogel System for Long-term Release of Cell-secreted Cytokines and Bioprinted In Situ Wound Cell Delivery. J. Biomed. Mater. Res. 105, 1986-2000. doi:10.1002/jbm.b.33736

Sodhi, H., and Panitch, A. (2021). Glycosaminoglycans in Tissue Engineering: A Review. Biomolecules 11, 29-22. doi:10.3390/biom11010029

Sonamuthu, J., Cai, Y., Liu, H., Kasim, M. S. M., Vasanthakumar, V. R., Pandi, B., et al. (2020). MMP-9 Responsive Dipeptide-Tempted Natural Protein Hydrogel-Based Wound Dressings for Accelerated Healing Action of Infected Diabetic Wound. Int. J. Biol. Macromolecules 153, 1058-1069. doi:10.1016/j.ijbiomac.2019.10.236

Sproul, E. P., Nandi, S., Roosa, C., Schreck, L., and Brown, A. C. (2018). Biomimetic Microgels with Controllable Deformability Improve Healing Outcomes. Adv. Biosys. 2, 1800042. doi:10.1002/adbi.201800042

Sun, G. (2017). Pro-Regenerative Hydrogel Restores Scarless Skin during Cutaneous Wound Healing. Adv. Healthc. Mater. 6, 1700659. doi:10.1002/ adhm.201700659

Sun, G., Zhang, X., Shen, Y.-I., Sebastian, R., Dickinson, L. E., Fox-Talbot, K., et al. (2011). Dextran Hydrogel Scaffolds Enhance Angiogenic Responses and Promote Complete Skin Regeneration During Burn Wound Healing. Proc. Natl. Acad. Sci. 108, 20976-20981. doi:10.1073/pnas.1115973108

Sun, J., Tan, H., Liu, H., Jin, D., Yin, M., Lin, H., et al. (2020). A Reduced Polydopamine Nanoparticle-Coupled Sprayable PEG Hydrogel Adhesive with Anti-infection Activity for Rapid Wound Sealing. Biomater. Sci. 8, 6946-6956. doi:10.1039/d0bm01213k

Sun, X., Altalhi, W., and Nunes, S. S. (2016). Vascularization Strategies of Engineered Tissues and Their Application in Cardiac Regeneration. Adv. Drug Deliv. Rev. 96, 183-194. doi:10.1016/j.addr.2015.06.001

Tamahkar, E., Özkahraman, B., Süloğlu, A. K., İdil, N., and Perçin, I. (2020). A Novel Multilayer Hydrogel Wound Dressing for Antibiotic Release. J. Drug Deliv. Sci. Tech. 58, 101536. doi:10.1016/j.jddst.2020.101536

Tan, Q.-W., Tang, S.-L., Zhang, Y., Yang, J.-Q., Wang, Z.-L., Xie, H.-Q., et al. (2019). Hydrogel from Acellular Porcine Adipose Tissue Accelerates Wound Healing by Inducing Intradermal Adipocyte Regeneration. J. Invest. Dermatol. 139, 455-463. doi:10.1016/j.jid.2018.08.013

Tao, B., Lin, C., Deng, Y., Yuan, Z., Shen, X., Chen, M., et al. (2019). Coppernanoparticle-embedded Hydrogel for Killing Bacteria and Promoting Wound Healing with Photothermal Therapy. J. Mater. Chem. B 7, 2534-2548. doi:10.1039/C8TB03272F

Tavakoli, J., Mirzaei, S., and Tang, Y. (2018). Cost-Effective Double-Layer Hydrogel Composites for Wound Dressing Applications. Polymers 10, 305. doi:10.3390/polym10030305

Tavakoli, S., Mokhtari, H., Kharaziha, M., Kermanpur, A., Talebi, A., and Moshtaghian, J. (2020). A Multifunctional Nanocomposite spray Dressing of Kappa-Carrageenan-Polydopamine Modified $\mathrm{ZnO} / \mathrm{L}-$ Glutamic Acid for Diabetic Wounds. Mater. Sci. Eng. C 111, 110837. doi:10.1016/ j.msec.2020.110837

Tavakolizadeh, M., Pourjavadi, A., Ansari, M., Tebyanian, H., Seyyed Tabaei, S. J., Atarod, M., et al. (2021). An Environmentally Friendly Wound Dressing Based on a Self-Healing, Extensible and Compressible Antibacterial Hydrogel. Green. Chem. 23, 1312-1329. doi:10.1039/d0gc02719g 
Thamm, O. C., Koenen, P., Bader, N., Schneider, A., Wutzler, S., Neugebauer, E. A., et al. (2015). Acute and Chronic Wound Fluids Influence Keratinocyte Function Differently. Int. Wound J. 12, 143-149. doi:10.1111/iwj.12069

Thi, P. L., Lee, Y., Tran, D. L., Thi, T. T. H., Kang, J. I., Park, K. M., et al. (2020). In Situ forming and Reactive Oxygen Species-Scavenging Gelatin Hydrogels for Enhancing Wound Healing Efficacy. Acta Biomater. 103, 142-152. doi:10.1016/ j.actbio.2019.12.009

Tokatlian, T., Cam, C., and Segura, T. (2015). Porous Hyaluronic Acid Hydrogels for Localized Nonviral DNA Delivery in a Diabetic Wound Healing Model. Adv. Healthc. Mater. 4, 1084-1091. doi:10.1002/adhm.201400783

Tomita, K., Madura, T., Sakai, Y., Yano, K., Terenghi, G., and Hosokawa, K. (2013). Glial Differentiation of Human Adipose-Derived Stem Cells: Implications for Cell-Based Transplantation Therapy. Neuroscience 236, 55-65. doi:10.1016/ j.neuroscience.2012.12.066

Tran, N. Q., Joung, Y. K., Lih, E., and Park, K. D. (2011). In Situ forming and RutinReleasing Chitosan Hydrogels as Injectable Dressings for Dermal Wound Healing. Biomacromolecules 12, 2872-2880. doi:10.1021/bm200326g

Trengove, N. J., Stacey, M. C., Macauley, S., Bennett, N., Gibson, J., Burslem, F., Murphy, G., and Schultz, G. (1999). Analysis of the acute and chronic wound environments: The role of proteases and their inhibitors. Wound Repair and Regeneration 7, 442-452. doi:10.1046/j.1524-475X.1999.00442.x

Umehara, T., Mori, R., Mace, K. A., Murase, T., Abe, Y., Yamamoto, T., et al. (2019). Identification of Specific miRNAs in Neutrophils of Type 2 Diabetic Mice: Overexpression ofmiRNA-129-2-3pAccelerates Diabetic Wound Healing. Diabetes 68, 617-630. doi:10.2337/db18-0313

Upadhyay, A., Chattopadhyay, P., Goyary, D., Mitra Mazumder, P., and Veer, V. (2014). Ixora Coccinea Enhances Cutaneous Wound Healing by Upregulating the Expression of Collagen and Basic Fibroblast Growth Factor. ISRN Pharmacol. 2014, 1-9. doi:10.1155/2014/751824

Vega, S. L., Kwon, M. Y., Song, K. H., Wang, C., Mauck, R. L., Han, L., et al. (2018). Combinatorial Hydrogels with Biochemical Gradients for Screening 3D Cellular Microenvironments. Nat. Commun. 9, 1. doi:10.1038/s41467-01803021-5

Wan, W., Cai, F., Huang, J., Chen, S., and Liao, Q. (2019). A Skin-Inspired 3D Bilayer Scaffold Enhances Granulation Tissue Formation and Anti-infection for Diabetic Wound Healing. J. Mater. Chem. B 7, 2954-2961. doi:10.1039/ c8tb03341b

Wang, C., Li, G., Cui, K., Chai, Z., Huang, Z., Liu, Y., et al. (2021). Sulfated Glycosaminoglycans in Decellularized Placenta Matrix as Critical Regulators for Cutaneous Wound Healing. Acta Biomater. 122, 199-210. doi:10.1016/ j.actbio.2020.12.055

Wang, C., Wang, Q., Gao, W., Zhang, Z., Lou, Y., Jin, H., et al. (2018). Highly Efficient Local Delivery of Endothelial Progenitor Cells Significantly Potentiates Angiogenesis and Full-Thickness Wound Healing. Acta Biomater. 69, 156-169. doi:10.1016/j.actbio.2018.01.019

Wang, P., Huang, S., Hu, Z., Yang, W., Lan, Y., Zhu, J., et al. (2019). In Situ formed Anti-inflammatory Hydrogel Loading Plasmid DNA Encoding VEGF for Burn Wound Healing. Acta Biomater. 100, 191-201. doi:10.1016/j.actbio.2019.10.004

Wang, S., Xiong, Y., Chen, J., Ghanem, A., Wang, Y., Yang, J., et al. (2019). Three Dimensional Printing Bilayer Membrane Scaffold Promotes Wound Healing. Front. Bioeng. Biotechnol. 7, 348. doi:10.3389/fbioe.2019.00348

Wang, S., Zheng, H., Zhou, L., Cheng, F., Liu, Z., Zhang, H., et al. (2020). Nanoenzyme-Reinforced Injectable Hydrogel for Healing Diabetic Wounds Infected with Multidrug Resistant Bacteria. Nano Lett. 20, 5149-5158. doi:10.1021/acs.nanolett.0c01371

Wang, T., Wang, J., Wang, R., Yuan, P., Fan, Z., and Yang, S. (2019). Preparation and Properties of $\mathrm{ZnO} /$ sodium Alginate Bi-layered Hydrogel Films as Novel Wound Dressings. New J. Chem. 43, 8684-8693. doi:10.1039/c9nj00402e

Wang, Y., Garcia, C. R., Ding, Z., Gabrilska, R., Rumbaugh, K. P., Wu, J., et al. (2020). Adhesive, Self-Healing, and Antibacterial Chitosan Hydrogels with Tunable Two-Layer Structures. ACS Sust. Chem. Eng. 8, 18006-18014. doi:10.1021/acssuschemeng.0c05730

Webber, M. J., Tongers, J., Newcomb, C. J., Marquardt, K.-T., Bauersachs, J., Losordo, D. W., et al. (2011). Supramolecular Nanostructures that Mimic VEGF as a Strategy for Ischemic Tissue Repair. Proc. Natl. Acad. Sci. 108, 13438-13443. doi:10.1073/pnas.1016546108

Wei, Q., Duan, J., Ma, G., Zhang, W., Wang, Q., and Hu, Z. (2019). Enzymatic Crosslinking to Fabricate Antioxidant Peptide-Based Supramolecular Hydrogel for Improving Cutaneous Wound Healing. J. Mater. Chem. B 7, 2220-2225. doi:10.1039/c8tb03147a

Wise, L. M., Bodaan, C. J., Stuart, G. S., Real, N. C., Lateef, Z., Mercer, A. A., et al. (2018). Treatment of Limb Wounds of Horses with Orf Virus IL-10 and VEGFE Accelerates Resolution of Exuberant Granulation Tissue, but Does Not Prevent its Development. PLoS One 13, e0197223. doi:10.1371/ journal.pone.0197223

Wong, V. W., Rustad, K. C., Galvez, M. G., Neofytou, E., Glotzbach, J. P., Januszyk, M., et al. (2011). Engineered Pullulan-Collagen Composite Dermal Hydrogels Improve Early Cutaneous Wound Healing. Tissue Eng. Part A 17, 631-644. doi:10.1089/ten.tea.2010.0298

Wu, J., Wu, D., Mutschler, M. A., and Chu, C.-C. (2012). Cationic Hybrid Hydrogels from Amino-Acid-Based Poly(ester Amide): Fabrication, Characterization, and Biological Properties. Adv. Funct. Mater. 22, 3815-3823. doi:10.1002/adfm.201103147

Wu, J., Zhao, X., Wu, D., and Chu, C.-C. (2014). Development of a Biocompatible and Biodegradable Hybrid Hydrogel Platform for Sustained Release of Ionic Drugs. J. Mater. Chem. B 2, 6660-6668. doi:10.1039/c4tb00576g

Wu, J., Zhu, J., He, C., Xiao, Z., Ye, J., Li, Y., et al. (2016). Comparative Study of Heparin-Poloxamer Hydrogel Modified bFGF and aFGF for In Vivo Wound Healing Efficiency. ACS Appl. Mater. Inter. 8, 18710-18721. doi:10.1021/ acsami.6b06047

Xian, C., Gu, Z., Liu, G., and Wu, J. (2020). Whole Wheat Flour Coating with Antioxidant Property Accelerates Tissue Remodeling for Enhanced Wound Healing. Chin. Chem. Lett. 31, 1612-1615. doi:10.1016/j.cclet.2019.09.011

Xiao, J., Chen, S., Yi, J., Zhang, H. F., and Ameer, G. A. (2017). A Cooperative Copper Metal-Organic Framework-Hydrogel System Improves Wound Healing in Diabetes. Adv. Funct. Mater. 27, 1604872. doi:10.1002/ adfm.201604872

Xu, K., Cantu, D. A., Fu, Y., Kim, J., Zheng, X., Hematti, P., et al. (2013). Thiol-ene Michael-type Formation of Gelatin/poly(ethylene Glycol) Biomatrices for Three-Dimensional Mesenchymal Stromal/stem Cell Administration to Cutaneous Wounds. Acta Biomater. 9, 8802-8814. doi:10.1016/ j.actbio.2013.06.021

Xu, Q., Sigen, A., Gao, Y., Guo, L., Creagh-Flynn, J., Zhou, D., et al. (2018). A Hybrid Injectable Hydrogel from Hyperbranched PEG Macromer as a Stem Cell Delivery and Retention Platform for Diabetic Wound Healing. Acta Biomater. 75, 63-74. doi:10.1016/j.actbio.2018.05.039

$\mathrm{Xu}, \mathrm{Z}$., Han, S., Gu, Z., and Wu, J. (2020). Advances and Impact of Antioxidant Hydrogel in Chronic Wound Healing. Adv. Healthc. Mater. 9, 1901502. doi:10.1002/adhm.201901502

Xuan, X., Zhou, Y., Chen, A., Zheng, S., An, Y., He, H., et al. (2020). Silver Crosslinked Injectable bFGF-Eluting Supramolecular Hydrogels Speed up Infected Wound Healing. J. Mater. Chem. B 8, 1359-1370. doi:10.1039/ c9tb02331c

Yan, X., Fang, W.-W., Xue, J., Sun, T.-C., Dong, L., Zha, Z., et al. (2019). Thermoresponsive In Situ Forming Hydrogel with Sol-Gel Irreversibility for Effective Methicillin-Resistant Staphylococcus aureus Infected Wound Healing. ACS Nano 13, 10074-10084. doi:10.1021/acsnano.9b02845

Yao, M., Zhang, J., Gao, F., Chen, Y., Ma, S., Zhang, K., et al. (2019). New BMSCLaden Gelatin Hydrogel Formed In Situ by Dual-Enzymatic Cross-Linking Accelerates Dermal Wound Healing. ACS Omega 4, 8334-8340. doi:10.1021/ acsomega.9b00878

Yee, D., Hanjaya-Putra, D., Bose, V., Luong, E., and Gerecht, S. (2011). Hyaluronic Acid Hydrogels Support Cord-like Structures from Endothelial colony-forming Cells. Tissue Eng. Part A 17, 1351-1361. doi:10.1089/ten.tea.2010.0481

Ying, H., Zhou, J., Wang, M., Su, D., Ma, Q., Lv, G., et al. (2019). In Situ formed Collagen-Hyaluronic Acid Hydrogel as Biomimetic Dressing for Promoting Spontaneous Wound Healing. Mater. Sci. Eng. C 101, 487-498. doi:10.1016/ j.msec.2019.03.093

Yoon, D. S., Lee, Y., Ryu, H. A., Jang, Y., Lee, K.-M., Choi, Y., et al. (2016). Cell Recruiting Chemokine-Loaded Sprayable Gelatin Hydrogel Dressings for Diabetic Wound Healing. Acta Biomater. 38, 59-68. doi:10.1016/ j.actbio.2016.04.030

Zeng, Q., Qian, Y., Huang, Y., Ding, F., Qi, X., and Shen, J. (2021). Polydopamine Nanoparticle-Dotted Food Gum Hydrogel with Excellent Antibacterial Activity and Rapid Shape Adaptability for Accelerated Bacteria-Infected Wound Healing. Bioactive Mater. 6, 2647-2657. doi:10.1016/j.bioactmat.2021.01.035 
Zeng, Y., Zhu, L., Han, Q., Liu, W., Mao, X., Li, Y., et al. (2015). Preformed Gelatin Microcryogels as Injectable Cell Carriers for Enhanced Skin Wound Healing. Acta Biomater. 25, 291-303. doi:10.1016/j.actbio.2015.07.042

Zhang, L., Ma, Y., Pan, X., Chen, S., Zhuang, H., and Wang, S. (2018). A Composite Hydrogel of Chitosan/heparin/poly ( $\gamma$-Glutamic Acid) Loaded with Superoxide Dismutase for Wound Healing. Carbohydr. Polym. 180, 168-174. doi:10.1016/ j.carbpol.2017.10.036

Zhang, S., Hou, J., Yuan, Q., Xin, P., Cheng, H., Gu, Z., et al. (2020). Arginine Derivatives Assist Dopamine-Hyaluronic Acid Hybrid Hydrogels to Have Enhanced Antioxidant Activity for Wound Healing. Chem. Eng. J. 392, 123775. doi:10.1016/j.cej.2019.123775

Zhao, D.-H., Yang, J., Yao, M.-H., Li, C.-Q., Zhang, B., Zhu, D., et al. (2020). An In Situ Synthesis of Silver Nanoparticle-Loaded Genetically Engineered Polypeptide Nanogels for Antibacterial and Wound Healing Applications. Dalton Trans. 49, 12049-12055. doi:10.1039/d0dt00751j

Zhao, G., Usui, M. L., Lippman, S. I., James, G. A., Stewart, P. S., Fleckman, P., et al. (2013). Biofilms and Inflammation in Chronic Wounds. Adv. Wound Care 2, 389-399. doi:10.1089/wound.2012.0381

Zhao, H., Huang, J., Li, Y., Lv, X., Zhou, H., Wang, H., et al. (2020). ROSscavenging Hydrogel to Promote Healing of Bacteria Infected Diabetic Wounds. Biomaterials 258, 120286. doi:10.1016/j.biomaterials.2020.120286

Zhao, L., Niu, L., Liang, H., Tan, H., Liu, C., and Zhu, F. (2017a). PH and Glucose Dual-Responsive Injectable Hydrogels with Insulin and Fibroblasts as Bioactive Dressings for Diabetic Wound Healing. ACS Appl. Mater. Inter. 9, 37563-37574. doi:10.1021/acsami.7b09395

Zhao, W., Li, Y., Zhang, X., Zhang, R., Hu, Y., Boyer, C., et al. (2020). Photoresponsive Supramolecular Hyaluronic Acid Hydrogels for Accelerated Wound Healing. J. Controlled Release 323, 24-35. doi:10.1016/ j.jconrel.2020.04.014

Zhao, X., Liang, Y., Huang, Y., He, J., Han, Y., and Guo, B. (2020d). Physical Double-Network Hydrogel Adhesives with Rapid Shape Adaptability, Fast SelfHealing, Antioxidant and NIR/pH Stimulus-Responsiveness for MultidrugResistant Bacterial Infection and Removable Wound Dressing. Adv. Funct. Mater. 30, 1910748. doi:10.1002/adfm.201910748

Zhao, X., Wu, H., Guo, B., Dong, R., Qiu, Y., and Ma, P. X. (2017b). Antibacterial Anti-oxidant Electroactive Injectable Hydrogel as SelfHealing Wound Dressing with Hemostasis and Adhesiveness for Cutaneous Wound Healing. Biomaterials 122, 34-47. doi:10.1016/ j.biomaterials.2017.01.011
Zheng, Y., Yuan, W., Liu, H., Huang, S., Bian, L., and Guo, R. (2020). Injectable Supramolecular Gelatin Hydrogel Loading of Resveratrol and Histatin-1 for Burn Wound Therapy. Biomater. Sci. 8, 4810-4820. doi:10.1039/d0bm00391c

Zhou, F., Hong, Y., Liang, R., Zhang, X., Liao, Y., Jiang, D., et al. (2020). Rapid Printing of Bio-Inspired 3D Tissue Constructs for Skin Regeneration. Biomaterials 258, 120287. doi:10.1016/j.biomaterials.2020.120287

Zhou, G., A., R., Ge, H., Wang, L., Liu, M., Wang, B., et al. (2014). Research on a Novel Poly (Vinyl Alcohol)/lysine/vanillin Wound Dressing: Biocompatibility, Bioactivity and Antimicrobial Activity. Burns 40, 1668-1678. doi:10.1016/ j.burns.2014.04.005

Zhu, C., Zhao, J., Kempe, K., Wilson, P., Wang, J., Velkov, T., et al. (2017). A Hydrogel-Based Localized Release of Colistin for Antimicrobial Treatment of Burn Wound Infection. Macromol. Biosci. 17, 1600320. doi:10.1002/ mabi.201600320

Zhu, Q., Jiang, M., Liu, Q., Yan, S., Feng, L., Lan, Y., et al. (2018). Enhanced Healing Activity of Burn Wound Infection by a Dextran-HA Hydrogel Enriched with Sanguinarine. Biomater. Sci. 6, 2472-2486. doi:10.1039/c8bm00478a

Zhu, Y., Hoshi, R., Chen, S., Yi, J., Duan, C., Galiano, R. D., et al. (2016). Sustained Release of Stromal Cell Derived Factor-1 from an Antioxidant Thermoresponsive Hydrogel Enhances Dermal Wound Healing in Diabetes. J. Controlled Release 238, 114-122. doi:10.1016/j.jconrel.2016.07.043

Conflict of Interest: The authors declare that the research was conducted in the absence of any commercial or financial relationships that could be construed as a potential conflict of interest.

Publisher's Note: All claims expressed in this article are solely those of the authors and do not necessarily represent those of their affiliated organizations, or those of the publisher, the editors and the reviewers. Any product that may be evaluated in this article, or claim that may be made by its manufacturer, is not guaranteed or endorsed by the publisher.

Copyright (c) 2021 Fan, Saha and Hanjaya-Putra. This is an open-access article distributed under the terms of the Creative Commons Attribution License (CC BY). The use, distribution or reproduction in other forums is permitted, provided the original author(s) and the copyright owner(s) are credited and that the original publication in this journal is cited, in accordance with accepted academic practice. No use, distribution or reproduction is permitted which does not comply with these terms. 


\section{GLOSSARY}

AC Alternating Current

AMPs Antimicrobial Peptides

$\beta G$ beta-1,3/1,6-glucan

BG Bioglass

BMSCs Bone marrow mesenchymal stem cells

CeONs Cerium oxide nanoparticles

CMC Carboxymethyl chitosan

CNT Carbon nanotubes

CTS Chitosan-treated serum

Cur Curcumin

DACNC Dialdehyde-modified cellulose nanocrystal

Dex-AE Dextran-allyl isocyanate-ethylamine

DexIEME Dextran-isocyanatoethyl methacrylate-ethylamine

DFO Desferrioxamine

DVDMS Sinoporphyrin sodium

ECFCs Endothelial colony forming cells

ECM Extracellular matrix

EGF Epithelial growth factor

FGF Fibroblast growth factor

GAGs Glycosaminoglycans

GFs Growth factors

GO Graphene oxide

GSNO S-nitrosoglutathione

GTU Ureido-pyrimidinone modified gelatin

HA Hyaluronic acid

hASCs Human adipose-derived stem cells
HIF-1 $\boldsymbol{\alpha}$ Hypoxia inducible factor-1

hiPSC Human induced pluripotent stem cells

HP Heparin

HRP Horseradish peroxidase

HUCPVCs Human umbilical cord perivascular cells

MC Methylcellulose

MDP Multidomain peptide

MIP Macrophage inflammatory protein

MMP-9 Matrix metallopeptidase 9

MSCs Mesenchymal stromal cells

NO Nitric oxide

NPs Nanoparticles

Oct Octenidine

Odex Oxidized dextran

PCL Polycaprolactone

PDGF Platelet-derived growth factor

PEG Poly(ethylene glycol)

PLGA Poly(lactic-co-glycolic acid)

PRP Platelet rich plasma

QCS Quaternized chitosan

Res Resveratrol

ROS Reactive oxygen species

SOD Superoxide dismutase

SP Spirulina platensis

SrtA Sortase A

UPy Ureido-pyrimidinone

VEGF Vascular endothelial growth factor 